\title{
Functional Exploration of the Bacterial Type VI Secretion System in Mutualism: Azorhizobium caulinodans ORS571-Sesbania rostrata as a Research Model
}

\author{
Hsiao-Han Lin, ${ }^{1,2}$ Hsin-Mei Huang, ${ }^{1}$ Manda Yu, ${ }^{2}$ Erh-Min Lai, ${ }^{2}$ Hsiao-Lin Chien, ${ }^{1}$ and Chi-Te Liu ${ }^{1,3,+}$ \\ ${ }^{1}$ Institute of Biotechnology, National Taiwan University, No. 81, Chang-Xing St., Taipei 10617, Taiwan; ${ }^{2}$ Institute of Plant and \\ Microbial Biology, Academia Sinica, No. 128 Section 2, Academia Rd., Nankang, Taipei 11529, Taiwan; and ${ }^{3}$ Agricultural \\ Biotechnology Research Center, Academia Sinica
}

Accepted 2 March 2018.

\begin{abstract}
The bacterial type VI secretion system (T6SS) has been considered the armed force of bacteria because it can deliver toxin effectors to prokaryotic or eukaryotic cells for survival and fitness. Although many legume symbiotic rhizobacteria encode T6SS in their genome, the biological function of T6SS in these bacteria is still unclear. To elucidate this issue, we used Azorhizobium caulinodans ORS571 and its symbiotic host Sesbania rostrata as our research model. By using T6SS gene deletion mutants, we found that T6SS provides $A$. caulinodans with better symbiotic competitiveness when coinfected with a T6SS-lacking strain, as demonstrated by two independent T6SS-deficient mutants. Meanwhile, the symbiotic effectiveness was not affected by T6SS because the nodule phenotype, nodule size, and nodule nitrogen-fixation ability did not differ between the T6SS mutants and the wild type when infected alone. Our data also suggest that under several lab culture conditions tested, A. caulinodans showed no T6SS-dependent interbacterial competition activity. Therefore, instead of being an antihost or antibacterial weapon of the bacterium, the T6SS in A. caulinodans ORS571 seems to participate specifically in symbiosis by increasing its symbiotic competitiveness.
\end{abstract}

Gram-negative bacteria have evolved various secretion systems that can deliver specific proteins, polysaccharides, or transferable DNA to the environment or directly into target cells to help them gain better fitness in the complex, everchanging living niche (Tseng et al. 2009). The type VI secretion system (T6SS) is one of these systems and can be found in more than a quarter of the sequenced gram-negative bacterial genome (Coulthurst 2013). T6SS has been considered a nanoweapon able to attack other organisms in a contact-dependent manner

Funding: This research was supported by the Ministry of Science and Technology, Taiwan, R.O.C. grant numbers MOST 104-2633-B-002-012, 105-2313-B-002-045, and 106-3114-B-005-001 to Chi-Te Liu and MOST 104-2311-B-001-025-MY3 to Erh-Min Lai.

Current address for Hsin-Mei Huang: Leibniz Institut für NaturstoffForschung und Infektionsbiologie e.V. Hans-Knöll-Institut, Beutenbergstraße 11a, 07745 Jena, Germany.

${ }^{\dagger}$ Corresponding author: Chi-Te Liu; E-mail: chiteliu@ntu.edu.tw

*The $\boldsymbol{e}$-Xtra logo stands for "electronic extra" and indicates that four supplementary figures are published online.

(c) 2018 The American Phytopathological Society
(Alcoforado Diniz et al. 2015; Cianfanelli et al. 2016; Hachani et al. 2016). Recent findings also showed its participation in metal ion sequestration in a contact-independent manner (Lin et al. 2017; Si et al. 2017).

The T6SS is composed of 13 type six secretion (Tss) core proteins, namely TssA to TssM, which span the double membrane of a gram-negative bacteria (Basler 2015; Zoued et al. 2014). The core apparatus can be further divided into the nonsecreted module and secreted module. The nonsecreted module is composed of the membrane spanning the TssJLM complex, the baseplate TssAEFGK complex, and the cytoplasmic contractile sheath TssBC complex. The secretion module of T6SS contains VgrG (or TssI) and Hcp (or TssD), similar to the T4 phage tail tip and tail tube, respectively (Leiman et al. 2009). The tail tube-like structure is surrounded by the TssBC complex; and when triggered, the TssBC complex will contract and inject the secretion module into the target cell (Brackmann et al. 2017). After injection, ClpV (or TssH) can disassemble the TssBC complex through its AAA+ ATPase, which energizes the disassociation of T6SS (Basler et al. 2012; Bönemann et al. 2009). Because the Hcp-VgrG complex is sent outside of the cell when T6SS is in action, the secretion of Hcp or VgrG to the medium has been widely considered an effective indicator of T6SS activity (Lin et al. 2013; Schell et al. 2007; Zheng and Leung 2007). Because of stoichiometric differences, Hcp is more broadly used as a T6SS activity indicator than VgrG.

The outcome of T6SS activity in a contact-dependent manner is the delivery of toxic effector proteins into the target cell via the secreted module mentioned previously (Basler et al. 2013). After the effector proteins reach the target cell, the toxicity could lead to cell death if the target cell does not synthesize the cognate immunity protein for neutralization (Lien and Lai 2017). These target cells can be prokaryote or eukaryote cells. For example, Vibrio cholera can use its T6SS to kill bacteria such as Escherichia coli or eukaryotic cells such as amoeba (Pukatzki et al. 2006). Depending on the types of target cell, T6SS-dependent killing activity is referred to as antibacterial activity or antieukaryotic activity (Cianfanelli et al. 2016). However, because of its energy-consuming nature, T6SS is tightly regulated in many species and its activity can be observed only under certain conditions (Miyata et al. 2013; Silverman et al. 2012). For example, secretion of the T6SS-associated Hcp proteins in the plant pathogen Agrobacterium tumefaciens was silent with growth in neutral minimal medium ( $\mathrm{pH} 7.0$ ) but activated at acidic $\mathrm{pH} 5.5$ (Wu et al. 2012), the environment present in the intercellular space and the cell wall of plants (Rayle and Cleland 1992). Furthermore, the T6SS-dependent 
interbacterial competition among Agrobacterium tumefaciens siblings was evident only inside plant leaves but significantly reduced on an agar surface (Ma et al. 2014). In the study of a plant growth-promoting bacteria, Pseudomonas fluorescens MFE01, the Hcp secretion and antibacterial activity of MFE01 could be observed at $28^{\circ} \mathrm{C}$ but not $37^{\circ} \mathrm{C}$. Because MFE01 is an environmental strain that grows better at $30^{\circ} \mathrm{C}$ than $37^{\circ} \mathrm{C}$, the above results suggest that T6SS has stronger activity under conditions that resemble its natural habitat (Decoin et al. 2014). Activation of T6SS was also found in the mammalian gastrointestinal pathogen Salmonella typhimurium, in which T6SSdependent antibacterial activity was observed in the presence of bile salt (Sana et al. 2016). Therefore, T6SS is more likely to be activated when the bacteria accommodate in their ecological niches for better fitness.

Apart from pathogenic bacteria, T6SS gene homologs are also widely found in legume symbionts (Nelson and Sadowsky 2015). Before T6SS was documented in 2006 (Pukatzki et al. 2006), insertion of a transposon insertion in impaired in nodulation $J$ (impJ), later known as tssK, in Rhizobium leguminosarum RBL5523 enabled the bacterium to establish a successful symbiosis relationship with its nonhost legume Pisum sativum (Bladergroen et al. 2003; Roest et al. 1997). The above results suggest a role of T6SS in Rhizobium symbiotic ability. Since the symbiotic relationship between Rhizobium and legumes is highly specific, elucidation of how the legume plant recognizes its microsymbionts from nonsymbionts could provide ways to broaden the host range of critical crops in agriculture (Venkateshwaran 2015). Accordingly, T6SS may be one of the factors involved in the symbiotic ability. However, whether and how T6SS impacts symbiotic ability and whether it participates in the antibacterial activity in rhizobia remain to be elucidated.

In this study, we used Azorhizobium caulinodans ORS571 as a rhizobial model to reveal the biological function of T6SS. This bacterium can form both root and stem nodules with its tropical legume host Sesbania rostrata (Dreyfus and Dommergues 1981). Our analysis revealed that A. caulinodans harbors a complete T6SS gene cluster homolog. Furthermore, transcriptomic data demonstrated that these T6SS gene homologs in A. caulinodans ORS571 are expressed in both free-living and symbiotic conditions (Tsukada et al. 2009). A successful symbiotic relationship can be evaluated by two important factors, symbiotic effectiveness and symbiotic competitiveness. Symbiotic effectiveness describes how efficient a strain is to form nodules with its host plant, while symbiotic competitiveness describes the ability of a strain to outcompete other strains during infection (Bromfield and Jones 1979). Here, we address whether symbiotic effectiveness and symbiotic competitiveness are affected by T6SS in ORS571. We also performed the antibacterial competition assay to address whether T6SS of A. caulinodans harbors antibacterial activity like that of many bacteria. The results show that T6SS provides A. caulinodans with better symbiotic competitiveness but not effectiveness.

\section{RESULTS}

\section{Gene cluster of T6SS in A. caulinodans is closely related to those in $R$. leguminosarum and Agrobacterium tumefaciens.}

We used Kyoto Encyclopedia of Genes and Genomes (KEGG) PATHWAY (Kanehisa and Goto 2000), STRING 9.1 (Franceschini et al. 2013), Protein Homology/analogY Recognition Engine v2.0 (Phyre2) (Kelley et al. 2015), and a National Center for Biotechnology Information (NCBI) Conserved Domain search (CD-search) (Marchler-Bauer et al. 2017) to search for the homologs of T6SS in the A. caulinodans ORS571 genome (NCBI accession AP009384.1). The genome harbors one deduced
T6SS gene cluster (azc_2586 to azc_2605) (Fig. 1A; Table 1). Two hcp homologs were found in the T6SS gene cluster $\left(a z c_{-}\right.$ 2589 and $a z c \_2591$ ), but only one vgrG homolog (azc_2592) was identified in ORS571. We also identified an hcp homolog ( $a z c_{-}$ 0275) that lies outside of this T6SS cluster (Fig. 1A; Table 1). For clarity, we annotated the $h c p$ homologs residing in the main cluster as hcp1 (azc_2589) and hcp2 (azc_2591) and the one that resides outside the main cluster as hcp3 (azc_0275). The sequences of $h c p 1, h c p 2$, and $h c p 3$ share $57,5 \overline{6}$, and $54 \%$ amino acid identity, respectively, with the hcp of Agrobacterium tumefaciens C58 (atu4345). Some genes within the cluster did not show homology to T6SS core apparatus components, T6SS-associated genes, or any known T6SS effectors or immunity proteins. These genes are $a z c \_2588, a z c \_2590$, and azc_2593 (Fig. 1A; Table 1). Bioinformatics analysis revealed that $a z c \_2588$ is a putative $S$-adenosylmethionine (SAM)dependent methyltransferase, but no reliable conserved domain could be identified in $a z c \_2590$ and $a z c \_2593$. Intriguingly, although we could not find any conserved domain in $a z c \_2590$, it showed homology to $a z c \_0274$, which lies downstream of $h c p 3$ (Fig. 1A). We also analyzed the two genes that lie downstream of the T6SS main cluster, $a z c \_2606$ and $a z c \_2607$. Although the $a z c \_2606$ was annotated as $u b i E$ previously (Lee et al. 2008), we conducted a protein BLAST search and found the alignment coverage between Azc_2606 (UniProt A8IB41) and E. coli ubiE (UniProt P0A887) was $22 \%$ and only $24 \%$ identity in the aligned region (data not shown). We further analyzed this gene by an NCBI CD-search and found that the azc_2606 harbored a SAMdependent methyltransferase domain (E-value 1.14e-33) and a methyltransferase regulatory domain (E-value 7.07e-12). On the other hand, the $a z c \_2607$ encodes a putative thiC gene involved in thiamine biosynthesis (Suzuki et al. 2007).

We then performed phylogenetic clustering of T6SS of ORS571 by using conservative $t s s$ genes against selected nodule-forming symbionts and some pathogens (Fig. 1B). The ${ }_{t s s} C$ gene was chosen for the comparison because it is more conserved than the other T6SS genes, such as $t s s F$, $t s s G$, and tssM (Barret et al. 2013). T6SS subgroups (designated i1 to i5) defined by genome-wide analyses with sequenced bacteria (Boyer et al. 2009) were also included (Fig. 1B). Unlike the phylogenetics results previously reported with 16S rDNA, showing that A. caulinodans ORS571 is related more to Bradyrhizobium japonicum USDA110 than to Rhizobium leguminosarum or Mesorhizobium loti (Lee et al. 2008), the T6SS of A. caulinodans ORS571 is separated from that of B. japonicum and M. loti. Meanwhile, the T6SS of ORS571 was grouped with those of $R$. leguminosarum, the well-known plant growthpromoting bacterium (PGPB) Azospirillum lipoferum 4B, and the plant pathogen Agrobacterium tumefaciens C58, all belonging to T6SS group V (Fig. 1B, i5) according to (Boyer et al. 2009).

\section{T6SS hallmark protein Hcp detected in the cellular} but not extracellular fraction of $A$. caulinodans ORS571.

The T6SS homologous genes in A. caulinodans ORS571 were expressed when cultured in rich tryptone-yeast medium (TY), minimal medium (MMO), nod gene-inducing medium (MMO with $20 \mu \mathrm{M}$ naringenin), and in the symbiotic state (bacteroid) (Tsukada et al. 2009). Because Hcp is considered the hallmark protein of T6SS and its secretion reflects T6SS activity (Haapalainen et al. 2012; Lin et al. 2013; Murdoch et al. 2011), we first tried to detect Hcp protein levels in A. caulinodans ORS571 by using the Hcp-specific antibody generated against Agrobacterium tumefaciens C58 (anti-C58Hcp) (Wu et al. 2008). The recombinant $A$. caulinodans Hcp2 and Hcp3 were detectable by anti-C58Hcp (Fig. 2A), indicating the crossreactivity of this antibody against one or more azorhizobial Hcp proteins. By using this antibody, the azorhizobial Hcp proteins 
were detected in the cellular fraction under various culture conditions, such as TY, MMO, MMO with $20 \mu \mathrm{M}$ naringenin, and a free-living nitrogen-fixing situation (L2 medium [MMO without ammonium sulfate]) (Fig. 2A).
To determine the secretion activity and biological functions of T6SS in A. caulinodans, we constructed various T6SS inframe deletion mutants: $\Delta t s s J\left(\Delta a z c \_2586\right), \Delta t s s L\left(\Delta a z c \_2596\right)$, $\Delta t s s B\left(\Delta a z c \_2599\right)$, and $\Delta v g r G\left(\Delta a z c \_2592\right)$. These strains are
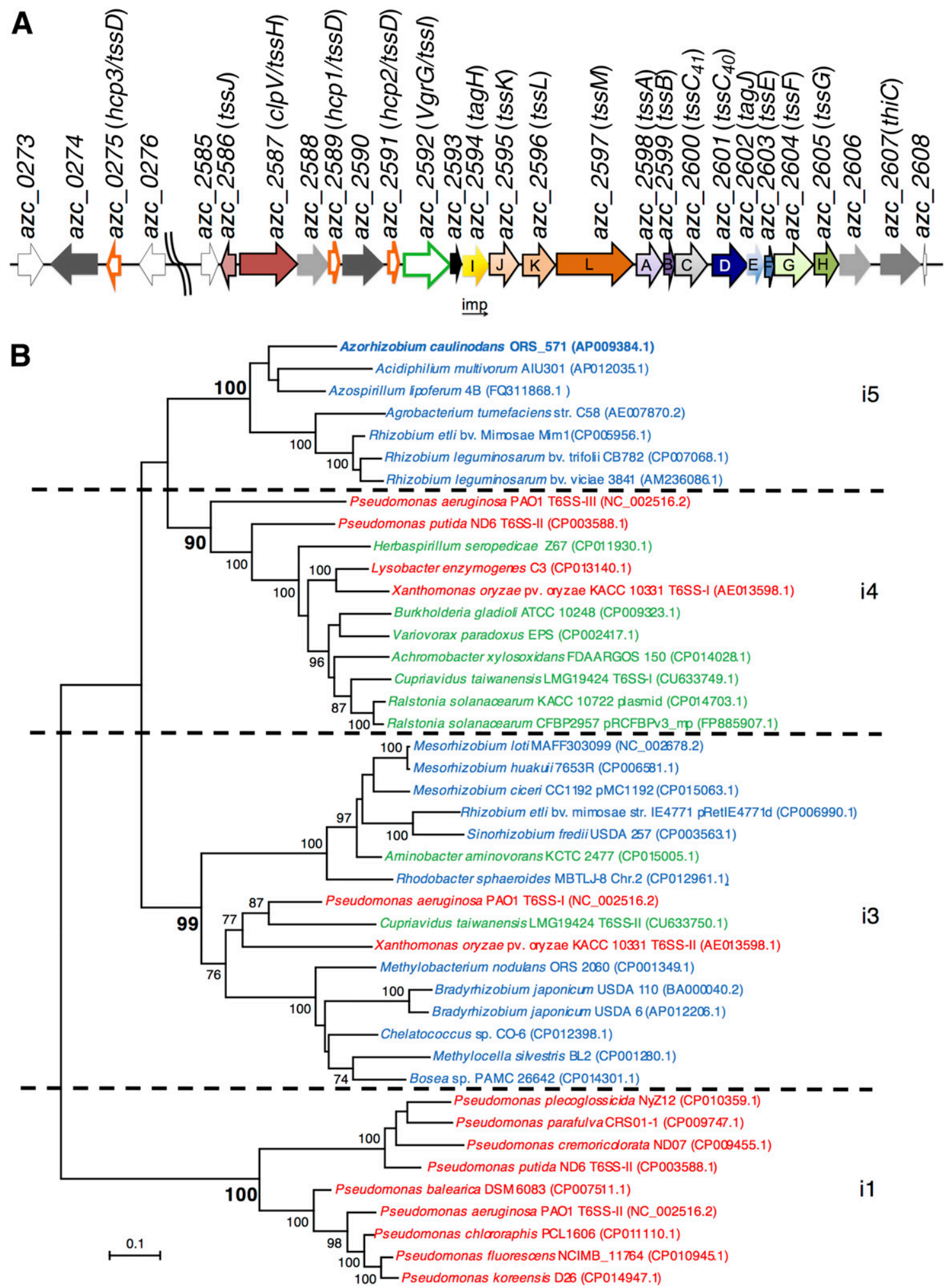

Fig. 1. Type VI secretion system (T6SS) gene cluster in Azorhizobium caulinodans ORS571 and phylogenetic analysis. A, T6SS gene cluster in A. caulinodans ORS571. The deduced T6SS conserved nonsecreted genes are shown in filled shades, with black boxed arrows indicating tss genes (type VI secretion) and nonboxed arrows indicating tag genes (type VI secretion-associated gene), based on nomenclature proposed by Shalom et al. (2007). Sequences were retrieved from the whole genome of A. caulinodans ORS571 in National Center for Biotechnology Information accession AP009384.1. B, A maximum-likelihood (ML) tree based on the partial $t s s C$ gene $(1,400 \mathrm{bp})$ of rhizobial symbionts and selected pathogens. Statistics of the ML model used to build the tree was GTR+G+I ML bootstrap support $(\geq 70 \%)$ is indicated at each node. The phylogenic analysis involved using MEGA6 (Tamura et al. 2013). Scale bar indicates the number of substitutions per site of the genes. The subgroups of T6SS suggested by (Boyer et al. 2009) are labeled i1 to i5. 
deficient in the outer-membrane protein TssJ, inner-membrane protein TssL, cytosolic tube sheath component TssB, and spike protein $\mathrm{VgrG}$ of T6SS, respectively. In addition, we also disrupted the whole imp operon (from azc_2594 to azc_2605) and designated it as an $\Delta i m p$ mutant. All mutations were confirmed by both sequencing and Southern hybridization (Supplementary Fig. S1). As a control for the secretion assay, the extracellular Hcp of Agrobacterium tumefaciens C58 was detected in high abundance as reported (Lin et al. 2014) while Hcp of A. caulinodans ORS571 was hardly detectable. The absence of signals could be due to the significantly weaker reactivity of the anti-C58Hcp antibody against Hcp of ORS571 (Fig. 2A and B). Hence, we then generated a Hcp antibody against ORS571 (anti-AcHcp) and repeated the secretion assay using anti-AcHcp. Although signals using anti-AcHcp were improved for cellular Hcp proteins, no Hcp proteins were detected in the extracellular fraction of wild-type or $\Delta t s s L$ grown in any of the media tested (Fig. 2C). These results suggest that T6SS component Hcp is expressed but not secreted under the in-vitro growth condition tested.

\section{T6SS-dependent antibacterial activity was not observed in A. caulinodans.}

No Hcp secretion could be detected under the growth conditions tested, but the T6SS machine may be assembled for effector delivery only when interacting with target cells. To examine the T6SS-mediated antibacterial activity of ORS571, we used E. coli DH10B or Agrobacterium tumefaciens as the target cells in the interbacterial competition assay. E. coli DH10B was chosen because it has been widely used as a susceptible target in T6SS-mediated antibacterial competition assays and it can also be cultured under $37^{\circ} \mathrm{C}$ (Basler et al. 2013; Decoin et al. 2014; Ma et al. 2014). Agrobacterium tumefaciens was chosen not only because it is a soilborne plant pathogen but, also, because its antibacterial activity has been well-demonstrated (Ma et al. 2014). E. coli survival did not differ under coculture with ORS571 or with any T6SS-deficient mutants or E. coli only (labeled in-), in either MMO (Fig. 3A) or rich medium
(Fig. 3B). Therefore, A. caulinodans may not have antibacterial activity against $E$. coli. For interbacterial competition assay against Agrobacterium tumefaciens, we used MMO (Fig. 3C), TY (Fig. 3D), or tobacco leaves (i.e., in-planta situation) (Fig.

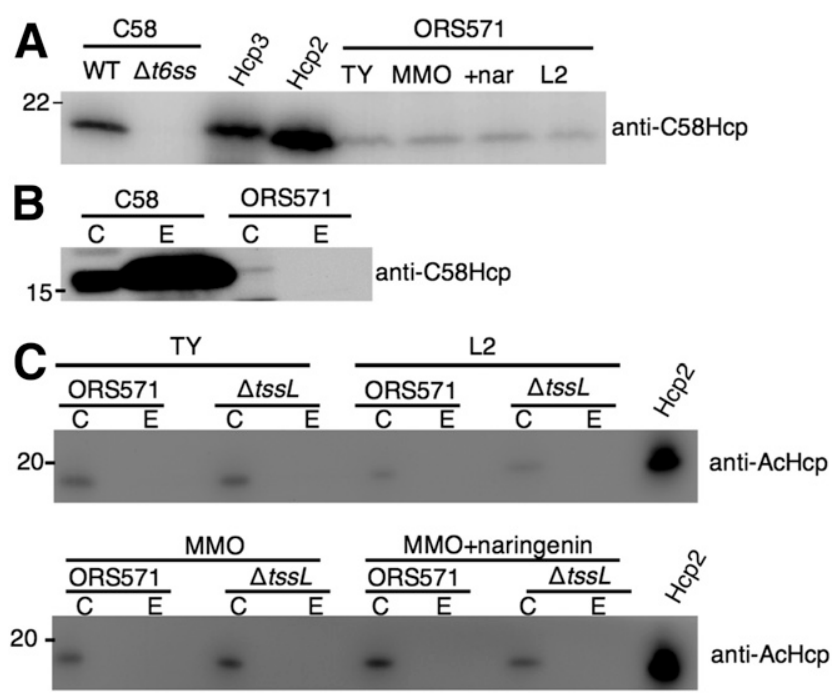

Fig. 2. Type VI secretion system hallmark protein Hcp can be found in the cellular but not extracellular fraction of Azorhizobium caulinodans ORS571. A, Hcp protein detected in the cellular fraction under all culture conditions tested. C58 WT $=$ Agrobacterium tumefaciens C58 wild type, C58 $\Delta t 6 s s=\Delta t 6 s$ Agrobacterium tumefaciens C58, Hcp3 = pET29a-Hcp3 (Azc_0275)-His/Escherichia coli BL21(DE3), Hcp2 = pET29a-Hcp (Azc_2591)-His/E. coli BL21 (DE3). A. caulinodans ORS571 cultured in tryptone yeast (TY) rich medium, minimal medium (MMO), MMO with naringenin (MMO+naringenin), representing nod gene-inducing condition, and the nitrogen-fixing state (L2 [MMO without ammonium sulfate]). B, No Hcp proteins were secreted into TY medium by A. caulinodans ORS571 WT; Agrobacterium tumefaciens C58 was a positive control for Hcp secretion, with anti-C58Hcp used for detecting Hcp expression. C, No Hcp secretion was detected in A. caulinodans ORS571 WT or $\Delta t s s L$ mutant in all culture conditions, with anti-AcHcp used for detecting Hcp expression. $\mathrm{C}=$ cellular fraction, $\mathrm{E}=$ extracellular fraction.

Table 1. Type VI secretion system (T6SS) gene homologs in Azorhizobium caulinodans ORS571 and their putative function ${ }^{\mathrm{a}}$

\begin{tabular}{|c|c|c|c|c|}
\hline ORF & Homologs & tss name & Putative function & Source \\
\hline$a z c \_0274$ & & & Homology to $a z c \_2590$ & STING 9.1 \\
\hline azc_0275 & $h c p$ & $t s s D$ & Secretion tube & KEGG \\
\hline$a z c \_2586$ & vas $D$ & tss $J$ & Membrane & KEGG \\
\hline azc_2587 & $\operatorname{clp} V$ & $t s s H$ & Cytoplasmic disassembler & KEGG \\
\hline$a z c \_2588$ & & & $\begin{array}{l}\text { Putative } S \text {-adenosylmethionine (SAM)- } \\
\text { dependent methyltransferases }\end{array}$ & CD-search, Phyre2 \\
\hline$a z c \_2589$ & $h c p$ & $t s s D$ & Secretion tube & KEGG \\
\hline$a z c \_2590$ & & & Homology to $a z c \_0274$ & CD-search, Phyre2 \\
\hline$a z c \_2591$ & $h c p$ & $t s s D$ & Secretion tube & KEGG \\
\hline$a z c \_2592$ & $\operatorname{vgrG}$ & $t s s I$ & Secretion spike & KEGG \\
\hline$a z c \_2593$ & & & Unknown function & CD-search, Phyre2 \\
\hline$a z c \_2594$ & impI & $\operatorname{tag} H$ & $\begin{array}{r}\text { T6SS-associated gene, FHA } \\
\text { domain-containing protein }\end{array}$ & STING 9.1 \\
\hline$a z c \_2595$ & impJ & $t s s K$ & Baseplate & STING 9.1 \\
\hline$a z c \_2596$ & impK & $t s s L$ & Membrane & KEGG \\
\hline$a z c \_2597$ & impL & tss $M$ & Membrane & KEGG \\
\hline$a z c \_2598$ & $i m p A$ & $t s s A$ & Baseplate & STING 9.1 \\
\hline$a z c \_2599$ & $i m p B$ & $t s s B$ & Cytoplasmic sheath & STING 9.1 \\
\hline$a z c \_2600$ & $\operatorname{impC}$ & tssC41 & Cytoplasmic sheath & STING 9.1 \\
\hline$a z c \_2601$ & $\operatorname{impD}$ & tssC40 & Cytoplasmic sheath & STING 9.1 \\
\hline$a z c \_2602$ & $i m p E$ & tagJ & T6SS-associated gene & STING 9.1 \\
\hline$a z c \_2603$ & $i m p F$ & $t s s E$ & Baseplate & STING 9.1 \\
\hline$a z c \_2604$ & impG & $t s s F$ & Baseplate & STING 9.1 \\
\hline$a z c \_2605$ & impH & $t s s G$ & Baseplate & STING 9.1 \\
\hline$a z c \_2606$ & & & SAM-dependent methyltransferase & CD-search \\
\hline azc_2607 & thiC & & Thiamine biosynthesis protein & Lee et al. 2008 \\
\hline
\end{tabular}

${ }^{\mathrm{a}} \mathrm{ORF}=$ open reading frame, KEGG $=$ Kyoto Encyclopedia of Genes and Genomes database, CD-search $=$ Conserved Domain search, Phyre2 $=$ Protein Homology/analogY Recognition Engine v2.0. 
3E) as the competition environments. Similar to the results of E. coli, the survival of Agrobacterium tumefaciens C58 cells remained at similar levels under coculture with ORS571, with any T6SS-deficiency mutants, or Agrobacterium tumefaciens itself under all conditions tested. In addition to the abovementioned interbacterial competitive assays with an attacker to target ratio of 100:1, no T6SS-dependent antibacterial activity could be observed in A. caulinodans under coculture at various ratios of attacker to target, including 1:1 and 10:1 (data not shown). Thus, we conclude that no direct antibacterial activity of T6SS of A. caulinodans is present, at least in our tested conditions.

\section{Deletion of T6SS had no adverse effects on symbiotic effectiveness.}

To understand whether T6SS interferes with the ability of ORS571 to form efficient symbiotic nodules, we inoculated the

A

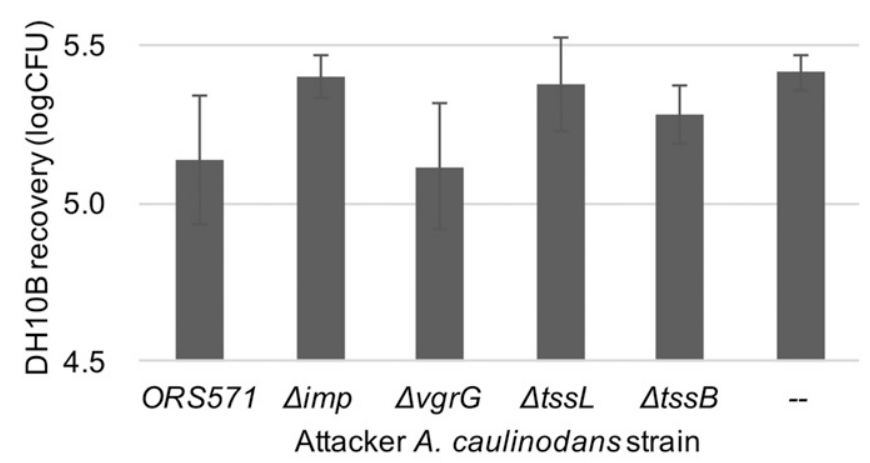

C

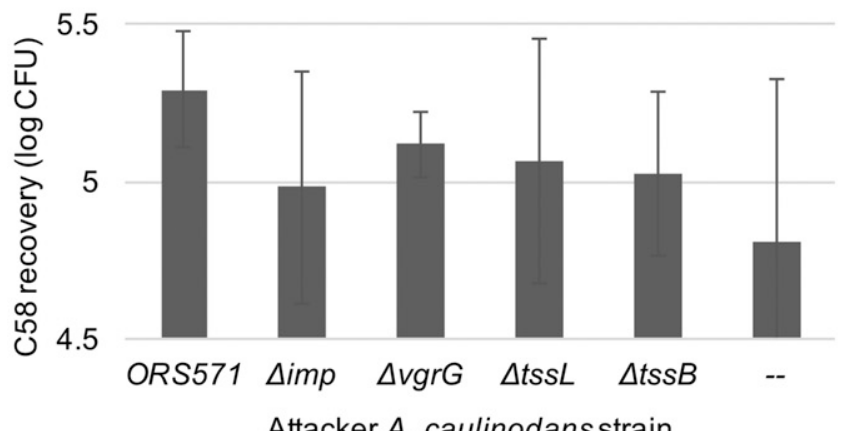

Attacker $A$. caulinodans strain

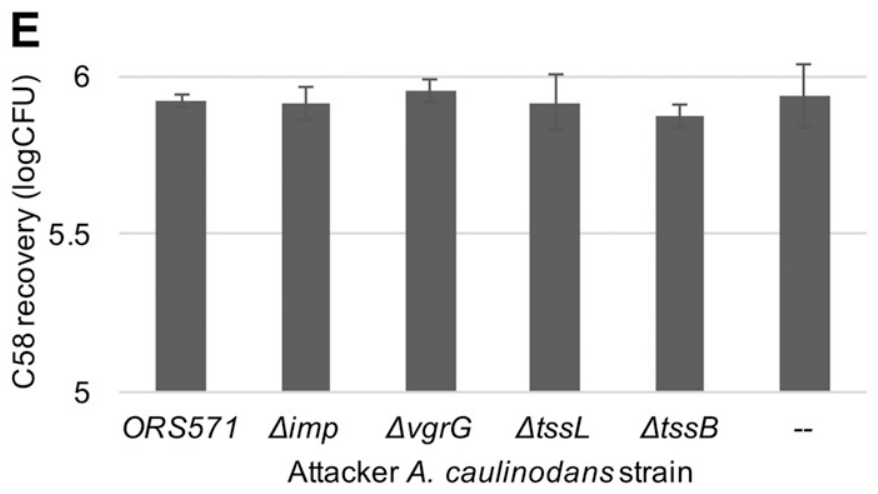

ORS571 and its derivatives on either stem or root of $S$. rostrata and observed the phenotype of stem nodules at 7 days postinfection (dpi) as well as that of root nodules at $20 \mathrm{dpi}$. The longitudinal sections of the stem nodules infected with T6SS mutants or ORS571 showed a red color, which indicates active nitrogen fixation in these nodules (Fig. 4A). Also, the symbiotic bacteria or the bacteroids fully occupied the infected plant cells in both ORS571- and Dimp-infected nodules (Fig. 4B). Moreover, the size of the nodules was comparable among the wild type and mutants (Fig. 4C). Nitrogen-fixing ability did not differ between nodules infected with ORS571 and any of the T6SS deletion mutants (Fig. 4D). On the other hand, root nodules cultured under a nitrogen-free condition was also evaluated. All the A. caulinodans-infected groups had shoot weight significantly higher than that of the nitrogen-free group $(-\mathrm{N})$ and significantly lower than that of the nitrogen supply group $(+\mathrm{N})$. However, there was no significant difference between wild
B

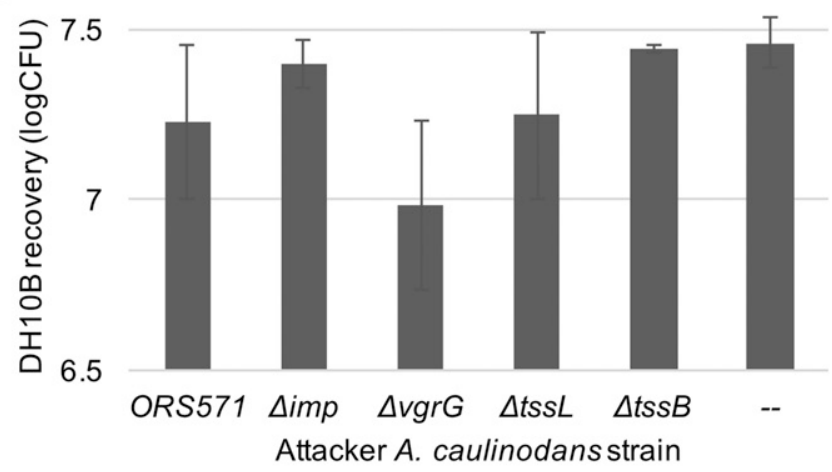

D

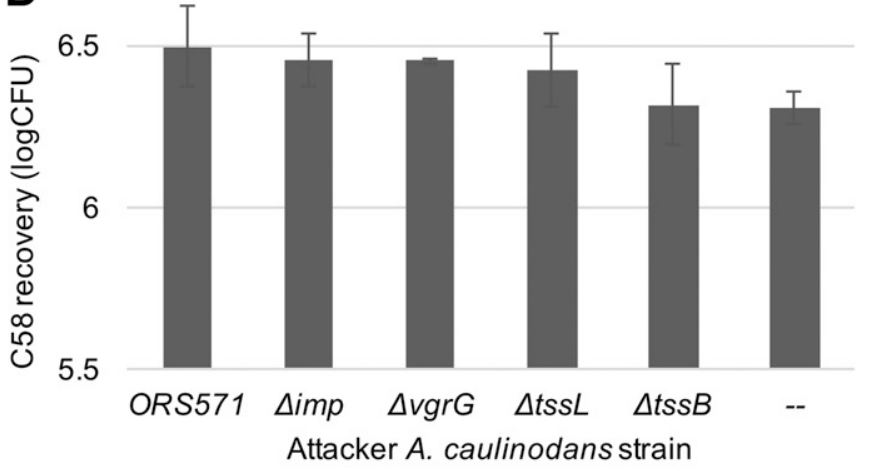

Fig. 3. Azorhizobium caulinodans did not show type VI secretion system-dependent antibacterial activity. A. caulinodans cells were cocultured with Escherichia coli DH10B harboring pRL662 plasmid at a ratio of 100:1 in A, minimal medium or B, rich medium. The same experiment was also performed between A. caulinodans and Agrobacterium tumefaciens in C, minimal medium, D, rich medium, or E, in tobacco leaves. Survival of E. coli or Agrobacterium tumefaciens cells was then quantified by resistance to gentamycin and streptomycin, respectively. The bar labeled in '-'represents the group without A. caulinodans attacker. Data are mean ( \pm standard deviation) results from one representative experiment and similar results were obtained from at least two independent experiments. 
type or T6SS mutant A. caulinodans-infected groups (Supplementary Fig. S2). Besides, there was no significant difference in the nodule number among the groups infected by the ORS571 derivatives. Taken together, it suggests that deficiency of T6SS in A. caulinodans does not affect its symbiotic effectiveness in $S$. rostrata.

\section{Deletion of T6SS reduced the symbiotic competitiveness} of $A$. caulinodans.

In addition to symbiotic effectiveness, symbiotic competitiveness is considered a major factor for successful nodulation (Bromfield and Jones 1979). Symbiotic competitiveness can be measured by the nodule occupancy rate of each rhizobium strain under mixed inoculation (Ji et al. 2017; Wielbo et al. 2010). To observe nodule occupancies, we tagged ORS571 and $\Delta i m p$ with $\beta$-glucuronidase (GUS) or $\beta$-galactosidase (LacZ) reporter and named the counterparts ORS571(pGusA), ORS571 (pLacZ), $\Delta i m p$ (pGusA), and $\Delta i m p(\mathrm{pLacZ}$ ), respectively (Fig. 5A). The stem nodules were formed synchronously and fixed nitrogen at $7 \mathrm{dpi}$ with the pairwise strain combination (Fig. 5B and C). The harvested stem nodules were cut in half, and the total number of GUS or lacZ hits in an individual nodule were determined by histochemical staining in the equal parts of the manually dissected nodule (Fig. 5D and E). With the mixed inoculation of ORS571 (pGusA) and $\Delta i m p(p L a c Z)$, the GUS-marked nodules significantly outnumbered the LacZ-marked ones, which indicates a higher nodule occupancy rate for ORS571 than for $\operatorname{\Delta imp}(P=$ $\left.3.17 \times 10^{-3}\right)($ Fig. $5 \mathrm{~F})$. Although not statistically significant, we noted that bacteria tagged with gusA showed a generally higher infection rate than those tagged with $l a c Z$, whether in the ORS571 (pGusA) plus ORS571(pLacZ) or $\Delta i m p($ pGusA) plus $\Delta i m p$ (pLacZ) group (Fig. 5F). To confirm the results from ORS571 (pGusA) and $\Delta \operatorname{imp}(\mathrm{pLacZ})$ were not due to reporter bias, we switched the labeling to verify the distinctive nodule occupancy rate was not derived from the experimental system itself. As shown for the ORS571(pLacZ) plus $\Delta i m p$ (pGusA) group (Fig. $5 \mathrm{~F}$ ), despite the $\Delta i m p$ possessing the GusA-tagged advantage, the median nodule occupancy rate was even higher for ORS571 (pLacZ) than $\Delta i m p(\mathrm{pGusA})$, although the difference was less pronounced $(P>0.01)$. We further confirmed such phenomenon by using ORS571 and another T6SS-deficient mutant, $\Delta t s s L$, as the competition pair. In group ORS571(pGusA) plus $\Delta t s s L$ (pLacZ), we also found that the occupancy of ORS571 was significantly higher than that of T6SS mutant $\left(P=4.27 \times 10^{-4}\right)$ (Supplementary Fig. S3). Accordingly, our results suggest that T6SS enhances A. caulinodans in symbiotic competitiveness.

To verify whether the higher infection rate for ORS571 under symbiosis derived from its higher competitive activity under the vegetative state, we tested their antibacterial activities and found no significant difference between wild type and the T6SSdeficient derivatives under either nutrient-rich (TY) or minimal nutrient (MMO) medium (Supplementary Fig. S4). We also determined the growth of these bacteria in MMO either singly or in equimolar mixtures and found no significant difference among them. Furthermore, we attempted to study the compatibility between the individual bacterium and the host by conducting a colonization assay with Sesbania seedlings. It did not differ significantly among the test groups, suggesting the
A
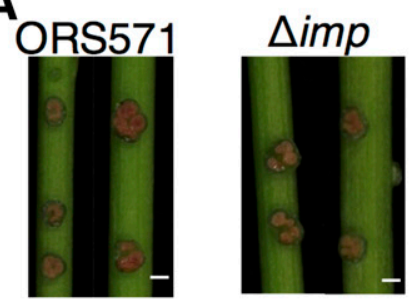

C

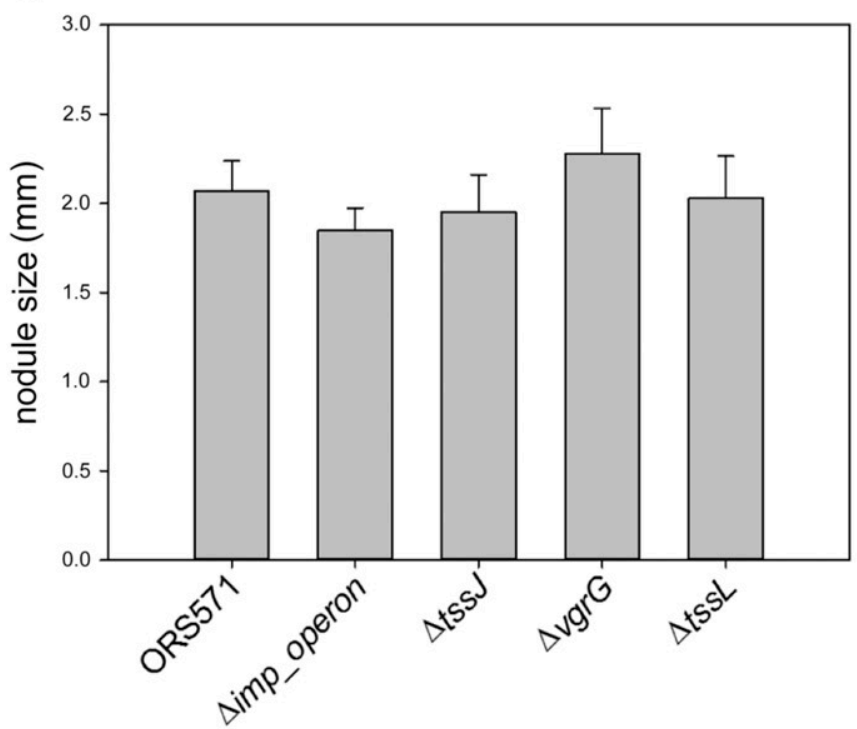

A. caulinodans ORS571 genotype

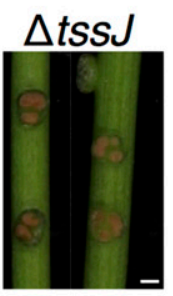

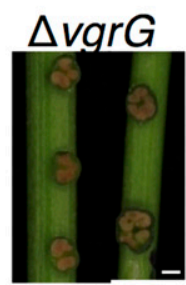

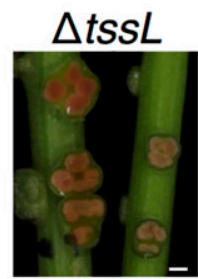

B
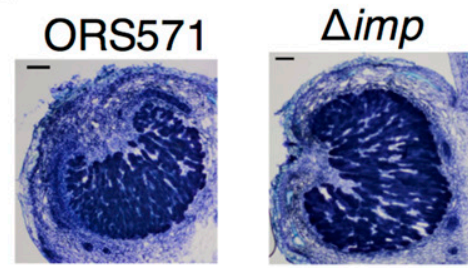

D

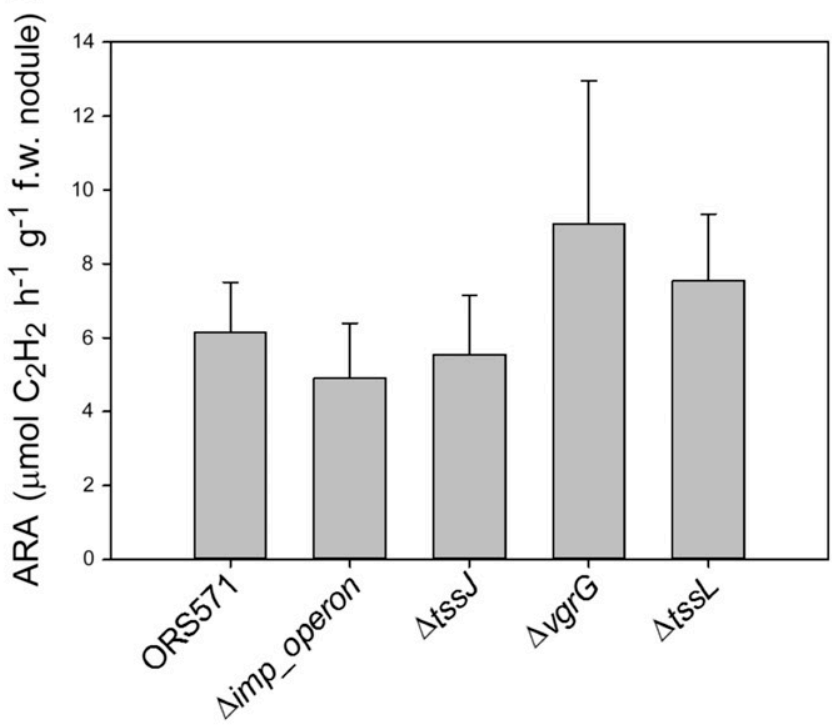

A. caulinodans ORS571 genotype

Fig. 4. Deletion of type VI secretion system had no adverse effects on symbiotic effectiveness. Sesbania rostrata stem nodules formed after infection by Azorhizobium caulinodans observed at 7 days postinoculation. A, Longitudinal sections of the nodule and B, bacteroid occupancy. Scale bars: 1 mm in A, $100 \mu \mathrm{m}$ in B. C, Nodule size and $\mathbf{D}$, nitrogen-fixing ability were measured. Data are mean ( \pm standard deviation). 
recovery of ORS571 from host plant was no better than that of the T6SS-deficient derivatives.

\section{DISCUSSION}

In this research, we identified a complete T6SS core apparatus homolog in A. caulinodans ORS571 genome interspersed with several unknown functional genes (azc_2588,azc_2590, and $a z c \_2593$ ) (Fig. 1A; Table 1). On the other hand, although two genes (azc_2606 and azc_2607) lay downstream of $a z c \_2605$ (tssG), the latter gene, azc_2607, is not likely part of the T6SS operon, due to the following reasons. First, the gap between $a z c \_2606$ and $a z c \_2607$ is 382 bp and there would be a thiamin pyrophosphate regulon at -245 of $a z c_{-} 2607$, which is located in the $5^{\prime}$ untranslated region of the thiamin metabolism-related gene (Novichkov et al. 2013), according to the RegPrecise database (December 2017). Second, we noted that the expression dynamics of the $a z c \_2607$ gene were not synchronized with its upstream genes (azc_2601 to azc_2606) under MMO, nod-factor induction, or bacterioid conditions (Tsukada et al. 2009). Accordingly, it suggests that $a z c \_2607$ is regulated separately from the imp operon. Taken together, we deduced that four unknown functional genes, azc_2588, azc_2590,azc_2593, and azc_2606, are associated with the T6SS main gene cluster in A. caulinodans.
A

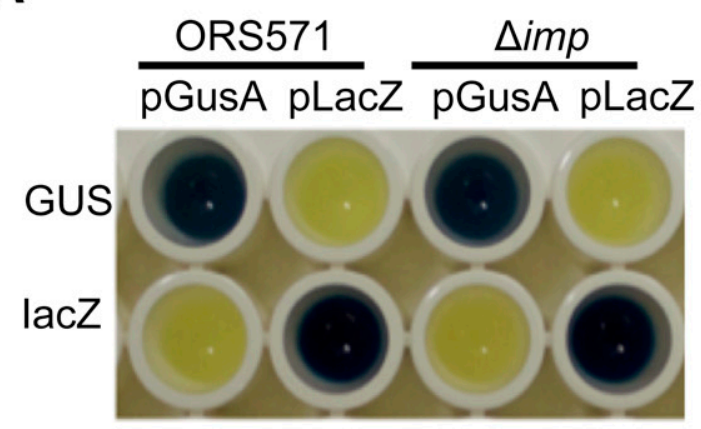

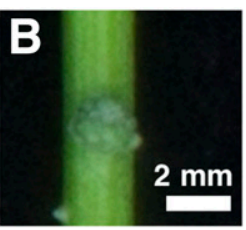
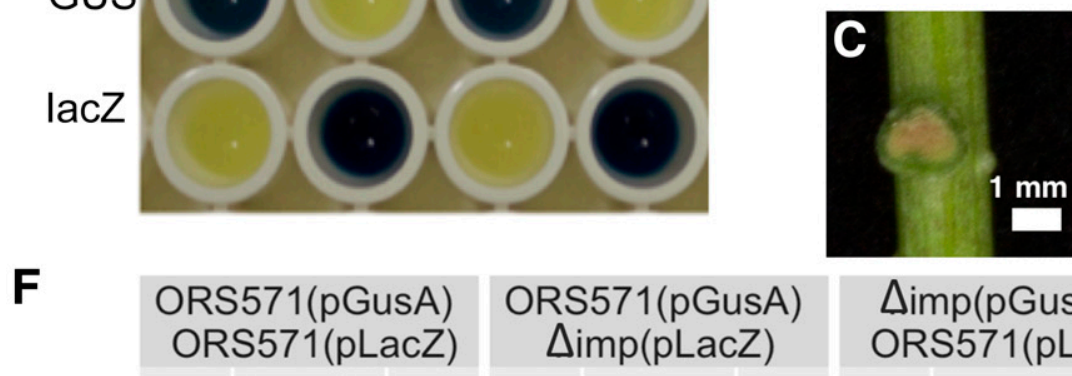

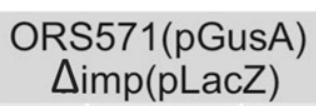

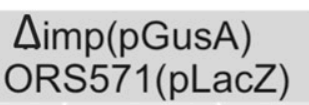

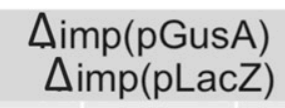

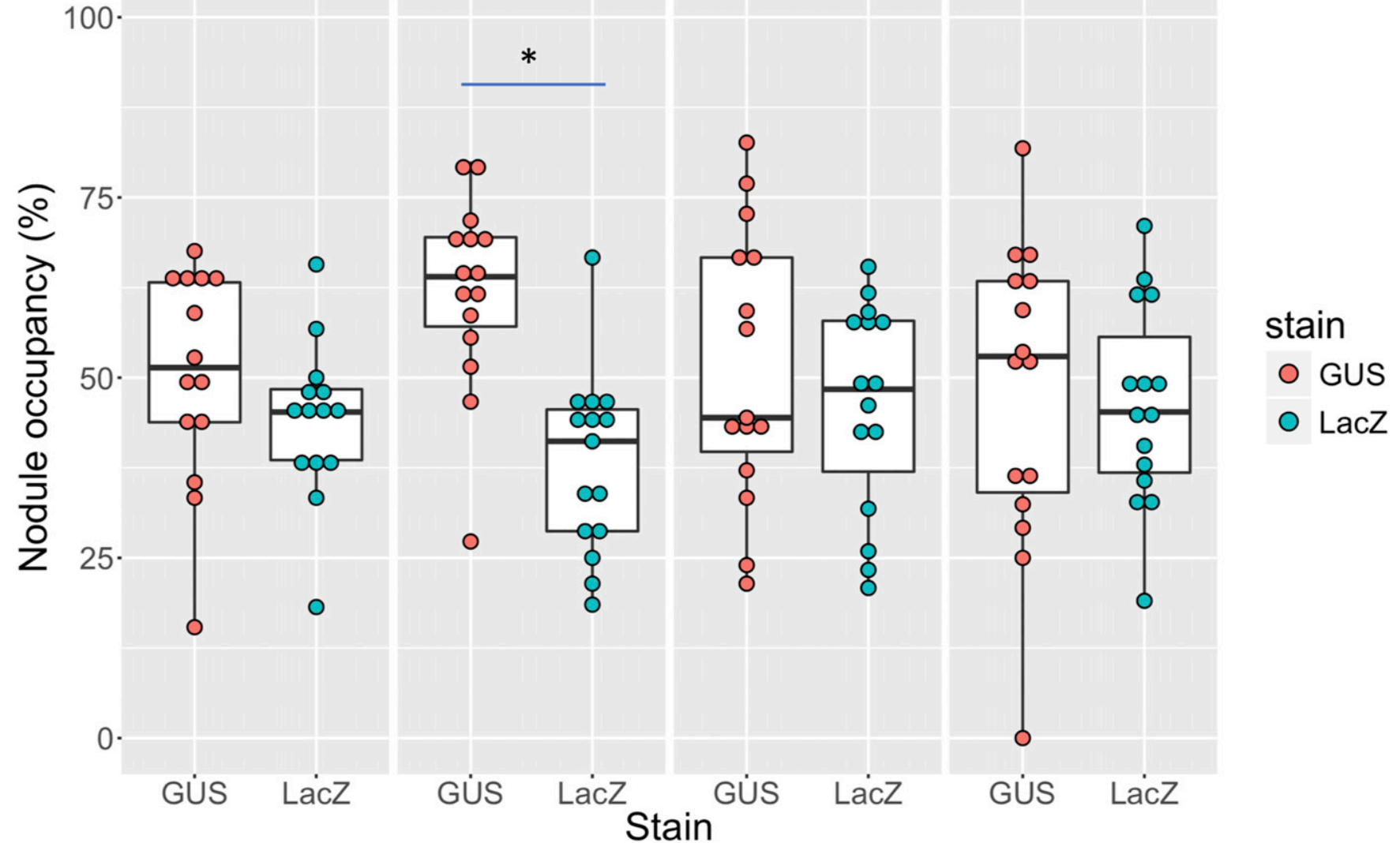

Fig. 5. Deletion of the type VI secretion system reduced the symbiotic competitiveness of Azorhizobium caulinodans. A, GUS and LacZ were constitutively expressed with strong staining signal in A. caulinodans ORS571 and $\Delta i m p$ cells grown in TY medium. B, Stem nodules 7 days old were $\mathbf{C}$, cut in half before staining. Each infection zone was stained fully with D, $\beta$-glucuronidase (GUS) or E, LacZ. F, Symbiotic competitiveness indicated by nodule occupancy between ORS571 and $\Delta i m p$. Horizontal lines are median, box edges are quartiles 1 and 3 and whiskers are 1.5 times of the interquartile range (IQR) from the box edges. Wilcoxon signed rank test with continuity correction test was used for statistical analysis with $P<0.01$ for statistical significance. An asterisk $(*)$ indicates $P=3.17 \times 10^{-3}$. 
The T6SS gene cluster is widespread in legume symbionts (Nelson and Sadowsky 2015), but little is known about their one or more biological functions. With A. caulinodans used as a model, our data suggest that T6SS could confer A. caulinodans with better symbiotic competitiveness, which enables it to outcompete its T6SS-lacking counterparts, either $\Delta i m p$ or $\Delta t s s L$, in a mixed inoculation situation (Fig. 5). Such outcompetitiveness was unlikely due to T6SS-dependent antibacterial activity under free-living states between ORS571 and $\Delta i m p$, which meet our expectation, as the genes mutated in $\Delta i m p$ were homologs known as T6SS core apparatus rather than as putative toxin or immunity proteins (Fig. 1; Table 1). The advantage of the wild-type ORS571 in symbiotic competitiveness was also unlikely due to the superior doubling time and competitive activity in low-nutrient microenvironments, as the colony-forming units (CFU) of ORS571 and $\Delta i m p$ did not differ when cultured in MMO medium, either singly or in a mixture. $S$. rostrata seedling colonization assay also demonstrated that the recovery of ORS571 was no better than that of $\Delta i m p$. This result suggests that the symbiotic competitiveness may not result from colonization ability, which has been demonstrated before (Duodu et al. 2008). The previous study that $R$. leguminosarum with T6SS disruption was able to form an effective nodule with its nonhost legume Pisum sativum (Bladergroen et al. 2003) could echo with our observations that T6SS of Rhizobium spp. play a role in symbiosis. However, with $R$. leguminosarum, the T6SS seems to play a negative role in the plant-microbe interaction. Rhizobium spp. may utilize the T6SS to obtain benefits from interacting with its host but have a negative role with its nonhost.

As no interbacterial competition advantages could be detected with the T6SS of A. caulinodans when interacting with E. coli or Agrobacterium tumefaciens (both in vitro and in planta) (Fig. 3), the T6SS of A. caulinodans is unlikely to function as an antibacterial weapon. The negative results of our interbacterial competition assay are also supported by the lack of putative bacterial toxin and immunity pairs identified in our comprehensive bioinformatics analysis. Furthermore, instead of being a bacterial nanoweapon, the T6SS could serve as an intercellular communication signal (Gallique et al. 2017a). The cell-to-cell communication function of T6SS has been demonstrated in several bacteria such as Proteus mirabilis, Pseudomonas fluorescens, and Pseudomonas aeruginosa (Gallique et al. 2017b; Lin et al. 2017; Wenren et al. 2013). In those cases, the T6SS participates in interbacterial communication and provides the bacterium with better fitness (Gallique et al. 2017a). Therefore, rhizobium may use the T6SS as a rhizobium-plant cell communication system that consists of the recognition code, which could be achieved by secreting some yet-to-be identified T6SSdependent effectors during the infection process. For instance, $a z c \_2588, a z c \_2590$, and $a z c \_2593$, which are each encoded adjacent to hcpl (azc_2589) and hcp2 (azc_2591) (Fig. 1), could be the potential effectors to serve this purpose. However, whether these proteins are T6SS effectors and whether they participate in rhizobium-plant cell communication remain to be elucidated.

In this study, we were unable to detect Hcp in the extracellular fraction, a hallmark of T6SS activity, under lab culture conditions (Fig. 2). As we were unable to observe the T6SSdependent antibacterial activity of $A$. caulinodans by testing the bacterial opponents, including $E$. coli and soilborne plant pathogen Agrobacterium tumefaciens, under various growth conditions (Fig. 3), the T6SS of A. caulinodans may be assembled and executed for Hcp secretion only when sensing one or more specific signals yet to be identified. In a previous study, Mougous et al. (2006) reported that, under laboratory in-vitro culture conditions, H1-T6SS of the wild-type Pseudomonas aeruginosa
PAO1 was not expressed and only activated for Hcp1 expression and secretion when a sensor kinase retS gene was mutated (Mougous et al. 2006). Strikingly, Hcp1 could be detected in pulmonary secretions of cystic fibrosis patients infected with Pseudomonas aeruginosa (Mougous et al. 2006). Therefore, the T6SS of A. caulinodans seems to be repressed by a negative regulator, which awaits future genome-wide screening for identifying the mutants de-repressing Hcp secretion activity.

Overall, our data suggest that unlike many animal and plant pathogens that utilize the T6SS as an antibacterial or antihost nanoweapon for interbacterial competition or pathogenesis, the T6SS of $A$. caulinodans may participate in symbiotic competitiveness but not effectiveness. Such function may be one of the rhizobium-host recognition codes for host specificity, which is an indispensable issue in legume-rhizobium symbiosis for sustainable agriculture. Thus, our results shed light on T6SS research on rhizobial symbionts and provide new insights for future attempts at expanding the host range of rhizobium.

\section{MATERIALS AND METHODS}

\section{Bacterial strains, media, and growth conditions.}

The bacterial strains used in this study are listed in Table 2 . A. caulinodans ORS571 was used as a parental strain for constructing mutants. Wild-type and mutant $A$. caulinodans strains were cultured at $37^{\circ} \mathrm{C}$ in rich TY, MMO (Dreyfus et al. 1983), MMO with $20 \mu \mathrm{M}$ naringenin (Goethals et al. 1989), or nitrogenfixing medium L2 (Dreyfus et al. 1983) with appropriate antibiotics, unless specified (Liu et al. 2011). Agrobacterium tumefaciens strains were cultured at $25^{\circ} \mathrm{C}$ in 523 medium (Kado and Heskett 1970). E. coli strains were cultured under $37^{\circ} \mathrm{C}$ in Luria-Bertani (LB) medium (Bertani 1951). The working concentrations of antibiotics were nalidixic acid $25 \mu \mathrm{g} \mathrm{ml}^{-1}$, kanamycin $50 \mu \mathrm{g} \mathrm{ml}^{-1}$, ampicillin $100 \mu \mathrm{g} \mathrm{ml}^{-1}$, gentamycin $50 \mu \mathrm{g} \mathrm{ml}^{-1}$, and streptomycin $12.5 \mu \mathrm{g} \mathrm{ml}^{-1}$. For doubling time and competitive activity in liquid medium measurements, $A$. caulinodans strains were grown in TY medium either singly or mixed in $1: 1$ ratio, with starting optical density at $600 \mathrm{~nm}\left(\mathrm{OD}_{600}\right)=0.01$. CFU were counted. Three biological replicates were performed. Statistical analysis involved single factor analysis of variance (ANOVA) for each timepoint. The significance threshold was $P<0.05$.

\section{Plant growth and bacterial inoculation.}

To facilitate germination, Sesbania rostrata seeds were treated with concentrated sulfate for $7 \mathrm{~min}$, followed by tap water flushing for $1 \mathrm{~h}$. The seeds were then washed with sterile water several times, were sprayed on trays, were covered by sterile vermiculite, and then, some sterile water was used to wet vermiculite. The seed-containing trays were kept in the dark for 3 days at $37^{\circ} \mathrm{C}$ to germinate. For the stem nodule test, germinated $S$. rostrata were transferred to horticulture soil and were grown for another 18 days at $35^{\circ} \mathrm{C}$ under $24 \mathrm{~h}$ light, as described previously (Liu et al. 2011). The plants were then inoculated with midlog phase A. caulinodans strains adjusted to $\mathrm{OD}_{600}=0.5$. Stem nodules were collected at $7 \mathrm{dpi}$. For the mixed inoculation assay, two strains of $A$. caulinodans were adjusted to $\mathrm{OD}_{600}=0.5$, mixed at a $1: 1$ ratio, and then, the mixture was diluted 50-fold before inoculation. For the root nodule test, the germinated $S$. rostrata were grown in the modified Leonard jars supplied with nitrogen-free Norris medium, as described previously (Fernández-López et al. 1998). A. caulinodans were inoculated at 7 days postgermination. Shoot fresh weight and nodule number were determined at 20 dpi. 


\section{Bioinformatics and phylogenetics analysis.}

The whole genome of $A$. caulinodans ORS571 was obtained from NCBI (accession AP009384.1). We searched T6SS homologous genes by using KEGG PATHWAY (release 68.1)

Table 2. Strains and plasmids used in this study

\begin{tabular}{|c|c|c|}
\hline $\begin{array}{l}\text { Strain or } \\
\text { plasmid }\end{array}$ & Relevant characteristics ${ }^{a}$ & $\begin{array}{l}\text { Source or } \\
\text { reference }\end{array}$ \\
\hline \multicolumn{3}{|c|}{ Azorhizobium caulinodans strains } \\
\hline ORS571 & Wild type; $\mathrm{Nx}^{\mathrm{R}}$ & $\begin{array}{l}\text { Dreyfus et al. } \\
1988\end{array}$ \\
\hline$\Delta i m p \_o p e r o n$ & $\begin{array}{l}\text { Entire imp_operon deletion mutant } \\
\text { (from } a z c \_2594 \text { to } a z c \_2605 \text { ); } \\
\mathrm{Nx}^{\mathrm{R}}\end{array}$ & This study \\
\hline$\Delta t s s J$ & $\begin{array}{l}\text { Deletion from }+7 \text { to }+594 \text { of } \\
a z c \_2586(t s s J, 600 \mathrm{bp}) ; \mathrm{Nx}^{\mathrm{R}}\end{array}$ & This study \\
\hline$\Delta v g r G$ & $\begin{array}{l}\text { Deletion from }+10 \text { to }+2,037 \\
\text { azc_2592 }(v g r G, 2,040 \mathrm{bp}) ; \mathrm{Nx}^{\mathrm{R}}\end{array}$ & This study \\
\hline$\Delta t s s L$ & $\begin{array}{l}\text { Deletion from }-4 \text { to }+1,467 \text { of } \\
a z c \_2596(t s s L, 1,485 \mathrm{bp}) ; \mathrm{Nx}^{\mathrm{R}}\end{array}$ & This study \\
\hline$\Delta t s s B$ & $\begin{array}{l}\text { Deletion from }+1 \text { to }+510 \text { of } \\
a z c \_2599(t s s B, 513 \mathrm{bp}) ; \mathrm{Nx}^{\mathrm{R}}\end{array}$ & This study \\
\hline $\begin{array}{l}\text { ORS571 } \\
\text { (pLacZ) }\end{array}$ & $\begin{array}{l}\text { ORS571 harboring pLacZ, lacZ; } \\
\mathrm{Nx}^{\mathrm{R}}, \mathrm{Tet}^{\mathrm{r}}\end{array}$ & This study \\
\hline $\begin{array}{l}\text { ORS571 } \\
\text { (pGusA) }\end{array}$ & $\begin{array}{l}\text { ORS571 harboring pFGusA, gusA; } \\
\mathrm{Nx}^{\mathrm{R}}, \mathrm{Tet}^{\mathrm{R}}\end{array}$ & This study \\
\hline$\Delta i m p(\mathrm{pLacZ})$ & $\begin{array}{l}\Delta i m p \_ \text {operon harboring } \mathrm{pLacZ} \\
\text { lacZ; } \mathrm{Nx}^{\mathrm{R}}, \mathrm{Tet}^{\mathrm{R}}\end{array}$ & This study \\
\hline$\Delta i m p($ pGusA $)$ & $\begin{array}{l}\Delta i m p \_ \text {operon harboring pGusA, } \\
\text { gusA; } \mathrm{Nx}^{\mathrm{R}}, \mathrm{Tet}^{\mathrm{R}}\end{array}$ & This study \\
\hline \multicolumn{3}{|c|}{ Escherichia coli strains } \\
\hline DH5a & $\begin{array}{l}\text { endA1 hsdR17 supE44 thi-1 recA1 } \\
\text { gyrA96 relA1 D(argF-lacZYA }) \\
\text { U169 } \$ 80 \text { lacZDM15 }\end{array}$ & Invitrogen \\
\hline S17-1 & $\begin{array}{l}\mathrm{Sp}^{\mathrm{r}} ; \mathrm{RP} 4 \text { tra region, mobilizer } \\
\text { strain, for conjugation }\end{array}$ & Simon et al. 1983 \\
\hline DH10B & $\begin{array}{l}\mathrm{F}^{-} \text {mcrA } \Delta(\text { mrr-hsdRMS-mcrBC }) \\
\text { Ф80lacZ } \Delta \mathrm{M} 15 \Delta \text { lacX74 rec } 11 \\
\text { end } 1 \text { ara } 139 \Delta(\text { ara leu }) 7697 \\
\text { gal } \mathrm{U} \text { gal } \mathrm{K} \text { rpsL nupG } \lambda-\end{array}$ & Invitrogen \\
\hline \multicolumn{3}{|c|}{ Agrobacterium tumefaciens strains } \\
\hline C58 & $\begin{array}{l}\text { Wild-type strain containing } \\
\text { nopaline-type plasmid pTiC58 }\end{array}$ & $\begin{array}{l}\text { Lin and Kado } \\
1977\end{array}$ \\
\hline$\Delta t 6 s s$ & $\begin{array}{l}\text { Entire } t 6 s s \text { gene cluster deletion } \\
\text { mutant }\end{array}$ & Lin et al. 2014 \\
\hline \multicolumn{3}{|l|}{ Plasmids } \\
\hline pK18mobsacB & $\begin{array}{l}\text { sacB mobolizable cloning vector, } \\
\mathrm{Km}^{\mathrm{R}}\end{array}$ & $\begin{array}{l}\text { Schäfer et al. } \\
1994\end{array}$ \\
\hline pRL662 & $\begin{array}{l}\text { Broad-host range vector derived } \\
\text { from pBBR1MCS- } 2, \mathrm{Gm}^{\mathrm{R}}\end{array}$ & $\begin{array}{l}\text { Vergunst et al. } \\
2000\end{array}$ \\
\hline 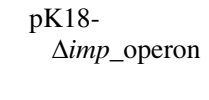 & $\begin{array}{l}\text { Plasmid used to generate ORS571- } \\
\text { Aimp_operon, pK18mobsacB } \\
\text { backbone, } \mathrm{Km}^{\mathrm{R}}\end{array}$ & This study \\
\hline $\mathrm{pK} 18-\Delta t s s J$ & $\begin{array}{l}\text { Plasmid used to generate ORS571- } \\
\Delta t s s J \text {, pK18mobsacB backbone, } \\
\mathrm{Km}^{\mathrm{R}}\end{array}$ & This study \\
\hline $\mathrm{pK} 18-\Delta v g r G$ & $\begin{array}{l}\text { Plasmid used to generate ORS571- } \\
\Delta v \operatorname{gr} G, \mathrm{pK} 18 \text { mobsacB backbone, } \\
\mathrm{Km}^{\mathrm{R}}\end{array}$ & This study \\
\hline pK18- $\Delta t s s L$ & $\begin{array}{l}\text { Plasmid used to generate ORS571- } \\
\Delta t s s L, \text { pK18mobsacB backbone, } \\
\mathrm{Km}^{\mathrm{R}}\end{array}$ & This study \\
\hline $\mathrm{pK} 18-\Delta t s s B$ & $\begin{array}{l}\text { Plasmid used to generate ORS571- } \\
\Delta t s s B, \mathrm{pK} 18 \text { mobsacB backbone, } \\
\mathrm{Km}^{\mathrm{R}}\end{array}$ & This study \\
\hline pFAJ1703 & $\begin{array}{l}\text { Promoter assay vector, RK2- } \\
\text { derived, with promoterless lacZ, } \\
\mathrm{Amp}^{\mathrm{R}}, \mathrm{Tet}^{\mathrm{R}}\end{array}$ & $\begin{array}{l}\text { Dombrecht et al. } \\
2001\end{array}$ \\
\hline pLacZ & $\begin{array}{l}\text { pFAJ1703 derived, constitutive } \\
\text { lacZ expression, } \mathrm{Amp}^{\mathrm{R}}, \mathrm{Tet}^{\mathrm{R}}\end{array}$ & This study \\
\hline pGusA & $\begin{array}{l}\text { pFAJ1703 derived, constitutive } \\
\text { gusA expression, } \mathrm{Amp}^{\mathrm{R}}, \mathrm{Tet}^{\mathrm{R}}\end{array}$ & This study \\
\hline
\end{tabular}

${ }^{a} \mathrm{Nx}^{\mathrm{R}}, \mathrm{Tet}^{\mathrm{R}}, \mathrm{Km}^{\mathrm{R}}, \mathrm{Gm}^{\mathrm{R}}, \mathrm{Amp}^{\mathrm{R}}=$ Resistance to nalidixic acid, tetracycline, kanamycin, gentamycin, and ampicillin, respectively.
(Kanehisa and Goto 2000) and STRING (v 9.1) (Franceschini et al. 2013). For the genes lying in the T6SS gene cluster that could not be identified to be related to T6SS, we used Phyre2 (Kelley et al. 2015) and CD-search (September 2017) (MarchlerBauer et al. 2017) to identify conserved domains. Phylogenetics analysis was conducted with MEGA6 (Tamura et al. 2013). The statistics model used to build the maximum-likelihood (ML) tree shown in Figure 1 was GTR+G+I, based on the partial $t s s C$ gene $(1,400 \mathrm{bp})$ of rhizobial symbionts and selected pathogens. ML bootstrap support is indicated, the scale bar indicates the number of substitutions per site for genes, and i1 to i5 represent the subgroups of T6SS suggested by (Boyer et al. 2009).

\section{Construction and confirmation of T6SS gene-deletion mutants.}

Gene-deletion mutants were constructed as described (Liu et al. 2011). In brief, about 500 bp immediately upstream and downstream of the deleted codons were amplified and combined by using splicing by overlap extension polymerase chain reaction (PCR) (Table 3 ). The products were then cloned into pK18mobsacB. After sequencing the product, the plasmids were transformed into $E$. coli $\mathrm{S} 17-1$ as a conjugation donor to ORS571. After conjugating plasmid-harbor E. coli S17-1 and ORS571, the single crossover strains were selected by kanamycin. The strains were then grown on TY medium without antibiotics at $37^{\circ} \mathrm{C}$ for $24 \mathrm{~h}$, then, were plated onto a $10 \%$ sucrosecontaining TY plate for selection of the second crossover strain. The gene deletion in the strains was confirmed by sequencing and by Southern hybridization. For sequencing, the genomic DNA was first amplified using primers flanking the deleted regions and was then subjected to DNA sequencing to ensure a complete miss in the deletion codons. Southern blotting and digoxigenin (DIG) labeling were conducted according to the DIG application manual (Roche), except for the adoption of the alkaline transfer method in the capillary transfer step (Reed and Mann 1985). The following DIG-labeled PCR probes were prepared, using the primer pairs shown in parentheses: probe-tss $J$ (Azc_2586-P5 plus Azc_2586-P6), probe-vgrG (imp_operon-P1 plus Azc_2592-P6), probe-tssL (Azc_2596-P5 plus Azc_2596P7), probe-tssB (Azc_2599-P8 plus Azc_2599-P9), probe-nodD (nodD-P5 plus nodD -P7), and probe-G (Azc_0874-P3 plus Azc_0874-P4).

\section{Antibody generation.}

pET29a-Hcp2-His(BL21(DE3) was used for Hcp-His purification. Briefly, cells were cultured overnight until the stationary phase and were then subcultured for another $3 \mathrm{~h}$ to reach the midlog phase. The midlog phase cells were induced with $0.4 \mathrm{mM}$ isopropyl $\beta$-D-1-thiogalactopyranoside, for $3 \mathrm{~h}$ at $37^{\circ} \mathrm{C}$, before disruption by using the EmulsiFlex-C3 homogenizer (Avestin Inc.) under 18,000 pounds per square inch. The harvested crude proteins were then purified using a Ni Sepharose 6 Fast Flow column (GE healthcare). For antibody production, the Ni column-purified proteins were further purified using HiTrap Q FF (GE healthcare), following the user manual. The purified proteins were then used for antibody production in rabbits.

\section{Protein secretion assay.}

The secretion assay for A. caulinodans and Agrobacterium tumefaciens strains was performed as described (Lin et al. 2014), unless specified. A. caulinodans strains were adjusted to $\mathrm{OD}_{600}=$ 1.0 with TY medium and were then grown at $37^{\circ} \mathrm{C}$ for another $6 \mathrm{~h}$ before they were harvested at $4^{\circ} \mathrm{C}, 8,000$ relative centrifugal force (rcf) for $10 \mathrm{~min}$. The pellet was used as a cellular protein sample and the supernatant as an extracellular protein sample. The pellet was mixed with $2 \times$ protein sample buffer directly, 
was boiled for $10 \mathrm{~min}$, then was centrifuged at $4^{\circ} \mathrm{C}, 10,000 \mathrm{rcf}$ for $10 \mathrm{~min}$ to remove cell debris. Supernatant was passed first through a $0.22-\mu \mathrm{m}$ filter (Millipore), then, each milliliter of sample was mixed with $30 \mu \mathrm{l}$ of $1 \%$ sodium deoxycholate and was incubated on ice for $10 \mathrm{~min}$ before the addition of $150 \mu \mathrm{l}$ trichloroacetic acid (TCA), in each sample, for overnight incubation at $4^{\circ} \mathrm{C}$. The TCA-precipitated supernatant was centrifuged at $4^{\circ} \mathrm{C}, 16,000 \mathrm{rcf}$ for $30 \mathrm{~min}$, then, all the liquid was carefully removed. The remaining protein pellet was resuspended with $10 \mu \mathrm{l}$ of $1 \mathrm{M}$ Tris-base, followed by adding $10 \mu \mathrm{l}$ of $2 \times$ protein sample buffer.

\section{Western blot analysis.}

Proteins resolved by $12.5 \%$ sodium dodecyl sulfatepolyacrylamide gel electrophoresis were transferred to nitrocellulose membrane (Millipore) and were then incubated at room temperature for $1 \mathrm{~h}$ with the primary polyclonal antibody against Hcp encoded by Agrobacterium tumefaciens (antiC58Hcp, dilution 1:2,500), as described by Lin et al. (2014), and against Hcp2-His (anti-AcHcp, dilution 1:5,000), generated by rabbit immunization (Yao-Hong Biotechnology Inc.), and then, the secondary antibody horseradish peroxidaseconjugated goat antirabbit (dilution 1:10,000) (Millipore) at room temperature for $1 \mathrm{~h}$. Chemiluminescence was used for signal development and visualization by the BioSpectrum $\mathrm{AC}$ imaging system (UVP).

\section{Symbiotic nitrogen-fixing activities of stem nodules.}

Nitrogen-fixing activities of stem nodules were determined by acetylene reduction assay (ARA) and were defined as $\mathrm{C}_{2} \mathrm{H}_{4}$ produced per hour per gram of nodule fresh weight. Stem nodules were peeled from plants and were placed into 18-ml Hungate-type tubes. The air in the headspace of each tube was replaced with $10 \% \mathrm{C}_{2} \mathrm{H}_{2}$. The samples were then incubated at $37^{\circ} \mathrm{C}$ for $1 \mathrm{~h}$. Then, $500 \mu \mathrm{l}$ of the sample was injected into a gas chromatography G3000 (Hitachi) equipped with a HayeSep T 80/100 volume (Supelco). Fresh stem-nodule weight was measured. Statistical analysis involved single factor ANOVA. The significance threshold was $P<0.05$.

\section{Antibacterial competition assay.}

A. caulinodans ORS571 and its derivative strains, Agrobacterium tumefaciens C58, and E. coli pRL662(DH10B) were used for the antibacterial competition assay. Bacterial cultures were washed with $0.9 \% \mathrm{NaCl}(\mathrm{wt} / \mathrm{vol})$ and were adjusted to $\mathrm{OD}_{600}=1.0$ for A. caulinodans and 0.01 for Agrobacterium tumefaciens or $E$. coli. Then, cultures were mixed at equal volume (ratio 100:1) and $10 \mu \mathrm{l}$ of the mixture was spotted on

Table 3. Primers used in this study

\begin{tabular}{|c|c|c|}
\hline Primer & Sequence $\left(5^{\prime}-3^{\prime}\right)$ & Restriction site \\
\hline \multicolumn{3}{|c|}{ Gene deletion and Southern hybridization } \\
\hline imp_operon-P1 & cggaattcCCATCACCATCAAGAACAACC & EcoRI \\
\hline imp_operon-P2 & actgagcacccaggcgagGGGCACCATCAGCTTGAGAT & \\
\hline imp_operon-P3 & CTCGCCTGGGTGCTCAGT & \\
\hline imp_operon-P4 & ccgaagcttTAGAAACGGTCAGGGAGCTG & HindIII \\
\hline Azc_2586-P1 & cggaattcTCTCATCATCGACACCCATC & EcoRI \\
\hline Azc_2586-P2 & tagaaaatggtagcgtgcggCТСТТССССТТСТGAGCCG & \\
\hline Azc_2586-P3 & CCGCACGCTACCATTTTCTA & \\
\hline Azc_2586-P4 & ccgaagcttCCGTAATGAGCGAGAATGAGC & HindIII \\
\hline Azc_2586-P5 & CGGGCGCAGGTCATAGAA AAT & \\
\hline Azc_2586-P6 & GCTCAGAAGGGGAAGAGGG & \\
\hline Azc_2592-P1 & cggaattcATCTCAACGCCAACAGGAGA & EcoRI \\
\hline Azc_2592-P2 & ctccatcgatccectctcaGTCACTCATGCGATCCCCTC & \\
\hline Azc_2592-P3 & TGAGAGGGGATCGATGGAG & \\
\hline Azc_2592-P4 & ccgaagcttTCCAGCACCCAGTCATTGTC & HindIII \\
\hline Azc_2592-P6 & CTCCATCGATCCCCTCTCA & \\
\hline Azc_2596-P1 & cggaattcCCGGTGGAGCAAATTCGAGA & EcoRI \\
\hline Azc_2596-P2 & ctattgcggcgtgagaacTCCСТTCCAGTGATCAGGACG & \\
\hline Azc_2596-P3 & GTTCTCACGCCGCAATAG & \\
\hline Azc_2596-P4 & ccgaagcttCGTACCAGGGCAGTTCATATT & HindIII \\
\hline Azc_2596-P5 & TGATGCTTCCGTCCTGATCA & \\
\hline Azc_2596-P7 & CGACACAGGTTGCTCATTGG & \\
\hline Azc_2599-P1 & gctctagagcCAACCTGCTCAACACTGTCC & $X b a \mathrm{I}$ \\
\hline Azc_2599-P2 & cttcagctgttcetcgttcgaGAGACTTCCCCGTTGACTG & \\
\hline Azc_2599-P3 & TCGAACGAGGAACAGCTGAAG & \\
\hline Azc_2599-P4 & ccgaagcttGTGGACTGGTCGAACTCAGA & HindIII \\
\hline Azc_2599-P8 & GCGTCATGGGCGATTTCTC & \\
\hline Azc_2599-P9 & ATCCTCCAGCGACTTAAAGC & \\
\hline nod̄-P1 & cggaattcCTCCAGCGCCTTCATCTTCT & EcoRI \\
\hline nodD-P2 & ttctgcgctgtccaaaatcatCTCCATCTACCCAGCATCCG & \\
\hline nodD-P3 & ATGATTTTGGACAGCGCAGAA & \\
\hline nodD-P4 & ccgaagcttTTCTGTCTGGCGAGGAAGAG & HindIII \\
\hline nodD-P5 & CGGATGCTGGGTAGATGGAG & \\
\hline nodD-P7 & CTCTTCGCTGCAGATGTCAC & \\
\hline Azc_0874-P3 & GAAGGCCCGGACGAGATAC & \\
\hline Azc_0874-P4 & ccgaagettGCGCCTGTCTCCTCCATG & HindIII \\
\hline \multicolumn{3}{|l|}{ Overexpressing Hcp } \\
\hline Azc0275-rv & gatatacatatgGCTATCTATGTGAACTACGAC & NdeI \\
\hline Azc0275-fw & ccgaagcttGCTCTTGGTGGTCGCGAG & HindIII \\
\hline Azc2591-fw & gatatacatatgGCCATCTACGTTAAATATGAC & NdeI \\
\hline Azc2591-rv & ccgaagcttCGAGCTCTTGGTGGTGGC & HindIII \\
\hline \multicolumn{3}{|c|}{$\beta$-Glucuronidase, LacZ tagged } \\
\hline pNodD-fw & ggggtaccccAGCCCGTCGGTGATTATCCA & KpnI \\
\hline pNodD-rv & gctctagagcCTCTTCGCTGCAGATGTCAC & $X b a \mathrm{I}$ \\
\hline
\end{tabular}


MMO or TY plates. The incubating temperature for A. caulinodans and $E$. coli competition was $37^{\circ} \mathrm{C}$, with $25^{\circ} \mathrm{C}$ used for competition between A. caulinodans and Agrobacterium tumefaciens. After incubation for $6 \mathrm{~h}$, bacterial colonies were collected and were resuspended in $1 \mathrm{ml}$ of $0.9 \% \mathrm{NaCl}$ (wt/vol). The suspension was then serially diluted and $100 \mu \mathrm{l}$ of the dilution was spread on 523 agar, for Agrobacterium tumefaciens, and on LB agar, for E. coli, with appropriate antibiotics for recovery. The procedure used for A. caulinodans ORS571 against the T6SS-deficient derivatives were the same as mentioned above, with minor modifications, the ratio was 50:1 and the incubation time was $16 \mathrm{~h}$. Streptomycin (15 ppm) was used for Agrobacterium tumefaciens recovery and gentamycin $(20 \mathrm{ppm})$ for $E$. coli and A. caulinodans recovery. All results were obtained from at least two independent experiments. Statistical analysis involved single-factor ANOVA with $P<0.05$ for statistical significance.

\section{Mixed inoculation assay.}

To determine nodule occupancy of respective pairwise inoculation, we tagged ORS571 and $\Delta i m p$ with GUS or LacZ reporter and named the counterparts ORS571(pGusA), ORS571 (pLacZ), $\Delta i m p(\mathrm{pGusA}$ ), and $\Delta i m p(\mathrm{pLacZ})$, respectively (Table 2). For any pairwise strain combination, they were mixed equally before inoculating on the stem of S. rostrata. S. rostrata was infected as described in the plant growth and bacterial inoculation section. The 7-dpi nodule was cut in half and was immersed in phosphate buffer ( $\mathrm{pH}$ 7.5) before all samples were collected. For GUS staining, nodules were fixed with acetone for $1 \mathrm{~h}$, then washed with phosphate buffer three times. Then, the nodules were stained with GUS substrate solution $\left(2.5 \mathrm{mM} \mathrm{K}_{3} \mathrm{Fe}\left[\mathrm{CN}_{6}\right], 500 \mathrm{mM} \mathrm{K}_{4} \mathrm{Fe}\left[\mathrm{CN}_{6}\right]\right.$, $0.5 \%[\mathrm{vol} / \mathrm{vol}]$ Triton X-100, $0.1 \mathrm{M}$ phosphate buffer [pH 7.5], and $0.5 \mathrm{mg}$ of 5-bromo-4-chloro-3-indolyl- $\beta$-D-glucuronic acid per milliliter]. For LacZ staining, the nodules were fixed with $1.25 \%$ ( vol/vol) glutaraldehyde for $1 \mathrm{~h}$, were washed with phosphate buffer three times, and were then stained with LacZ substrate solution $\left(2.5 \mathrm{mM} \mathrm{K} \mathrm{K}_{3} \mathrm{Fe}\left[\mathrm{CN}_{6}\right], 500 \mathrm{mM} \mathrm{K} \mathrm{K}_{4} \mathrm{Fe}\left[\mathrm{CN}_{6}\right]\right.$, $0.5 \%$ [vol/vol] Triton X-100, 0.1 M phosphate buffer [pH 7.5], $0.8 \mathrm{mg}$ of 5-bromo-4-chloro-3-indolyl- $\beta$-D-galactopyranoside per milliliter). Both GUS and LacZ staining was performed overnight before observation. Because the population distribution was not normally distributed, we used nonparametric statistics. The Wilcoxon signed rank test with continuity correction test was used for statistical analysis with $P<0.01$ for statistical significance.

\section{$S$. rostrata seedling colonization assay.}

The $S$. rostrata seedling colonization assay was performed as described by Liu et al. (2017), with a few modifications. In brief, bacterial cultures were grown separately and were adjusted to $\mathrm{OD}_{600}=0.5$, then were mixed in $1: 1$ ratio, immersing 2 -day-old $S$. rostrata seedlings for $24 \mathrm{~h}$. At $24 \mathrm{~h}$ postinoculation, the seedlings were taken out, were washed with sterile water four times to remove the unattached bacteria, were homogenized, and were suspended in sterile water. The suspensions were serially diluted, then spread on a plate for colony counting. Three independent experiments were performed.

\section{ACKNOWLEDGMENTS}

We thank C.-T. Huang for assisting with phylogenetic analysis.

\section{LITERATURE CITED}

Alcoforado Diniz, J., Liu, Y.-C., and Coulthurst, S. J. 2015. Molecular weaponry: Diverse effectors delivered by the type VI secretion system. Cell. Microbiol. 17:1742-1751.

Barret, M., Egan, F., and O'Gara, F. 2013. Distribution and diversity of bacterial secretion systems across metagenomic datasets. Environ. Microbiol. Rep. 5:117-126.
Basler, M. 2015. Type VI secretion system: Secretion by a contractile nanomachine. Philos. Trans. R. Soc. Lond. B Biol. Sci. 370:0021.

Basler, M., Ho, B. T., and Mekalanos, J. J. 2013. Tit-for-tat: Type VI secretion system counterattack during bacterial cell-cell interactions. Cell 152:884-894.

Basler, M., Pilhofer, M., Henderson, G. P., Jensen, G. J., and Mekalanos, J. J. 2012. Type VI secretion requires a dynamic contractile phage taillike structure. Nature 483:182-186.

Bertani, G. 1951. Studies on lysogenesis. I. The mode of phage liberation by lysogenic Escherichia coli. J. Bacteriol. 62:293-300.

Bladergroen, M. R., Badelt, K., and Spaink, H. P. 2003. Infection-blocking genes of a symbiotic Rhizobium leguminosarum strain that are involved in temperature-dependent protein secretion. Mol. Plant-Microbe Interact. 16:53-64.

Bönemann, G., Pietrosiuk, A., Diemand, A., Zentgraf, H., and Mogk, A. 2009. Remodelling of VipA/VipB tubules by ClpV-mediated threading is crucial for type VI protein secretion. EMBO J. 28:315-325.

Boyer, F., Fichant, G., Berthod, J., Vandenbrouck, Y., and Attree, I. 2009. Dissecting the bacterial type VI secretion system by a genome wide in silico analysis: What can be learned from available microbial genomic resources? BMC Genomics 10:104.

Brackmann, M., Nazarov, S., Wang, J., and Basler, M. 2017. Using force to punch holes: Mechanics of contractile nanomachines. Trends Cell Biol. 27:623-632.

Bromfield, E. S. P., and Jones, D. G. 1979. The competitive ability and symbiotic effectiveness of doubly labelled antibiotic resistant mutants of Rhizobium trifolii. Ann. Appl. Biol. 91:211-219.

Cianfanelli, F. R., Monlezun, L., and Coulthurst, S. J. 2016. Aim, load, fire: The type VI secretion system, a bacterial nanoweapon. Trends Microbiol. 24:51-62.

Coulthurst, S. J. 2013. The Type VI secretion system-A widespread and versatile cell targeting system. Res. Microbiol. 164:640-654.

Decoin, V., Barbey, C., Bergeau, D., Latour, X., Feuilloley, M. G. J., Orange, N., and Merieau, A. 2014. A type VI secretion system is involved in Pseudomonas fluorescens bacterial competition. PLoS One 9:e89411.

Dombrecht, B., Vanderleyden, J., and Michiels, J. 2001. Stable RK2derived cloning vectors for the analysis of gene expression and gene function in gram-negative bacteria. Mol. Plant-Microbe Interact. 14: 426-430.

Dreyfus, B., Garcia, J. L., and Gillis, M. 1988. Characterization of Azorhizobium caulinodans gen. nov., sp. nov., a stem-nodulating nitrogen-fixing bacterium isolated from Sesbania rostrata. Int. J. Syst. Bacteriol. 38:89-98.

Dreyfus, B. L., and Dommergues, Y. R. 1981. Nitrogen-fixing nodules induced by Rhizobium on the stem of the tropical legume Sesbania rostrata. FEMS Microbiol. Lett. 10:313-317.

Dreyfus, B. L., Elmerich, C., and Dommergues, Y. R. 1983. Free-living Rhizobium strain able to grow on $\mathrm{N}_{2}$ as the sole nitrogen source. Appl. Environ. Microbiol. 45:711-713.

Duodu, S., Brophy, C., Connolly, J., and Svenning, M. M. 2008. Competitiveness of a native Rhizobium leguminosarum biovar trifolii strain for nodule occupancy is manifested during infection. Plant Soil 318: 117-126.

Fernández-López, M., Goormachtig, S., Gao, M., D’Haeze, W., Van Montagu, M., and Holsters, M. 1998. Ethylene-mediated phenotypic plasticity in root nodule development on Sesbania rostrata. Proc. Natl. Acad. Sci. U.S.A. 95:12724-12728.

Franceschini, A., Szklarczyk, D., Frankild, S., Kuhn, M., Simonovic, M., Roth, A., Lin, J., Minguez, P., Bork, P., von Mering, C., and Jensen, L. J. 2013. STRING v9.1: Protein-protein interaction networks, with increased coverage and integration. Nucleic Acids Res. 41 (D1):D808-D815.

Gallique, M., Bouteiller, M., and Merieau, A. 2017a. The type VI secretion system: A dynamic system for bacterial communication? Front. Microbiol. 8:1454.

Gallique, M., Decoin, V., Barbey, C., Rosay, T., Feuilloley, M. G. J., Orange, N., and Merieau, A. 2017b. Contribution of the Pseudomonas fluorescens MFE01 type VI secretion system to biofilm formation. PLoS One 12:e0170770.

Goethals, K., Gao, M., Tomekpe, K., Van Montagu, M., and Holsters, M. 1989. Common nodABC genes in Nod locus 1 of Azorhizobium caulinodans: Nucleotide sequence and plant-inducible expression. Mol. Gen. Genet. 219:289-298

Haapalainen, M., Mosorin, H., Dorati, F., Wu, R.-F., Roine, E., Taira, S., Nissinen, R., Mattinen, L., Jackson, R., Pirhonen, M., and Lin, N.-C. 2012. Hcp2, a secreted protein of the phytopathogen Pseudomonas syringae pv. tomato DC3000, is required for fitness for competition against bacteria and yeasts. J. Bacteriol. 194:4810-4822.

Hachani, A., Wood, T. E., and Filloux, A. 2016. Type VI secretion and antihost effectors. Curr. Opin. Microbiol. 29:81-93. 
Ji, Z. J., Yan, H., Cui, Q. G., Wang, E. T., Chen, W. F., and Chen, W. X. 2017. Competition between rhizobia under different environmental conditions affects the nodulation of a legume. Syst. Appl. Microbiol. 40:114-119.

Kado, C. I., and Heskett, M. G. 1970. Selective media for isolation of Agrobacterium, Corynebacterium, Erwinia, Pseudomonas, and Xanthomonas. Phytopathology 60:969-976.

Kanehisa, M., and Goto, S. 2000. KEGG: Kyoto Encyclopedia of Genes and Genomes. Nucleic Acids Res. 28:27-30.

Kelley, L. A., Mezulis, S., Yates, C. M., Wass, M. N., and Sternberg, M. J. E. 2015. The Phyre2 web portal for protein modeling, prediction and analysis. Nat. Protoc. 10:845-858.

Lee, K. B., De Backer, P., Aono, T., Liu, C. T., Suzuki, S., Suzuki, T., Kaneko, T., Yamada, M., Tabata, S., Kupfer, D. M., Najar, F. Z., Wiley, G. B., Roe, B., Binnewies, T. T., Ussery, D. W., D’Haeze, W., Herder, J. D., Gevers, D., Vereecke, D., Holsters, M., and Oyaizu, H. 2008. The genome of the versatile nitrogen fixer Azorhizobium caulinodans ORS571. BMC Genomics 9:271.

Leiman, P. G., Basler, M., Ramagopal, U. A., Bonanno, J. B., Sauder, J. M., Pukatzki, S., Burley, S. K., Almo, S. C., and Mekalanos, J. J. 2009. Type VI secretion apparatus and phage tail-associated protein complexes share a common evolutionary origin. Proc. Natl. Acad. Sci. U.S.A. 106:4154-4159.

Lien, Y.-W., and Lai, E.-M. 2017. Type VI secretion effectors: Methodologies and biology. Front. Cell. Infect. Microbiol. 7:254.

Lin, B.-C., and Kado, C. I. 1977. Studies on Agrobacterium tumefaciens. VIII. Avirulence induced by temperature and ethidium bromide. Can. J. Microbiol. 23:1554-1561.

Lin, J., Zhang, W., Cheng, J., Yang, X., Zhu, K., Wang, Y., Wei, G., Qian, P.-Y., Luo, Z.-Q., and Shen, X. 2017. A Pseudomonas T6SS effector recruits PQS-containing outer membrane vesicles for iron acquisition. Nat. Commun. 8:14888.

Lin, J.-S., Ma, L.-S., and Lai, E.-M. 2013. Systematic dissection of the agrobacterium type VI secretion system reveals machinery and secreted components for subcomplex formation. PLoS One 8:e67647.

Lin, J.-S., Wu, H.-H., Hsu, P.-H., Ma, L.-S., Pang, Y.-Y., Tsai, M.-D., and Lai, E.-M. 2014. Fha interaction with phosphothreonine of TssL activates type VI secretion in Agrobacterium tumefaciens. PLoS Pathog. 10: e1003991.

Liu, C.-T., Lee, K.-B., Wang, Y.-S., Peng, M.-H., Lee, K.-T., Suzuki, S., Suzuki, T., and Oyaizu, H. 2011. Involvement of the azorhizobial chromosome partition gene (parA) in the onset of bacteroid differentiation during Sesbania rostrata stem nodule development. Appl. Environ. Microbiol. 77:4371-4382.

Liu, W., Yang, J., Sun, Y., Liu, X., Li, Y., Zhang, Z., and Xie, Z. 2017. Azorhizobium caulinodans transmembrane chemoreceptor TlpA1 involved in host colonization and nodulation on roots and stems. Front. Microbiol. 8:1327.

Ma, L.-S., Hachani, A., Lin, J.-S., Filloux, A., and Lai, E.-M. 2014. Agrobacterium tumefaciens deploys a superfamily of type VI secretion DNase effectors as weapons for interbacterial competition in planta. Cell Host Microbe 16:94-104.

Marchler-Bauer, A., Bo, Y., Han, L., He, J., Lanczycki, C. J., Lu, S., Chitsaz, F., Derbyshire, M. K., Geer, R. C., Gonzales, N. R., Gwadz, M., Hurwitz, D. I., Lu, F., Marchler, G. H., Song, J. S., Thanki, N., Wang, Z., Yamashita, R. A., Zhang, D., Zheng, C., Geer, L. Y., and Bryant, S. H. 2017. CDD/SPARCLE: Functional classification of proteins via subfamily domain architectures. Nucleic Acids Res. 45 (D1):D200-D203.

Miyata, S. T., Bachmann, V., and Pukatzki, S. 2013. Type VI secretion system regulation as a consequence of evolutionary pressure. J. Med. Microbiol. 62:663-676.

Mougous, J. D., Cuff, M. E., Raunser, S., Shen, A., Zhou, M., Gifford, C. A., Goodman, A. L., Joachimiak, G., Ordoñez, C. L., Lory, S., Walz, T., Joachimiak, A., and Mekalanos, J. J. 2006. A virulence locus of Pseudomonas aeruginosa encodes a protein secretion apparatus. Science 312:1526-1530.

Murdoch, S. L., Trunk, K., English, G., Fritsch, M. J., Pourkarimi, E., and Coulthurst, S. J. 2011. The opportunistic pathogen Serratia marcescens utilizes type VI secretion to target bacterial competitors. J. Bacteriol. 193:6057-6069.

Nelson, M. S., and Sadowsky, M. J. 2015. Secretion systems and signal exchange between nitrogen-fixing rhizobia and legumes. Front. Plant Sci. 6:491.

Novichkov, P. S., Kazakov, A. E., Ravcheev, D. A., Leyn, S. A., Kovaleva, G. Y., Sutormin, R. A., Kazanov, M. D., Riehl, W., Arkin, A. P., Dubchak, I., and Rodionov, D. A. 2013. RegPrecise 3.0-A resource for genome-scale exploration of transcriptional regulation in bacteria. BMC Genomics 14:745.

Pukatzki, S., Ma, A. T., Sturtevant, D., Krastins, B., Sarracino, D., Nelson, W. C., Heidelberg, J. F., and Mekalanos, J. J. 2006. Identification of a conserved bacterial protein secretion system in Vibrio cholerae using the Dictyostelium host model system. Proc. Natl. Acad. Sci. U.S.A. 103:1528-1533.
Rayle, D. L., and Cleland, R. E. 1992. The acid growth theory of auxininduced cell elongation is alive and well. Plant Physiol. 99:1271-1274.

Reed, K. C., and Mann, D. A. 1985. Rapid transfer of DNA from agarose gels to nylon membranes. Nucleic Acids Res. 13:7207-7221.

Roest, H. P., Mulders, I. H. M., Spaink, H. P., Wijffelman, C. A., and Lugtenberg, B. J. J. 1997. A Rhizobium leguminosarum biovar trifolii locus not localized on the sym plasmid hinders effective nodulation on plants of the pea cross-inoculation group. Mol. Plant-Microbe Interact. 10:938-941.

Sana, T. G., Flaugnatti, N., Lugo, K. A., Lam, L. H., Jacobson, A., Baylot, V., Durand, E., Journet, L., Cascales, E., and Monack, D. M. 2016. Salmonella typhimurium utilizes a T6SS-mediated antibacterial weapon to establish in the host gut. Proc. Natl. Acad. Sci. U.S.A. 113:E5044E5051.

Schäfer, A., Tauch, A., Jäger, W., Kalinowski, J., Thierbach, G., and Pühler, A. 1994. Small mobilizable multi-purpose cloning vectors derived from the Escherichia coli plasmids pK18 and pK19: Selection of defined deletions in the chromosome of Corynebacterium glutamicum. Gene 145:69-73.

Schell, M. A., Ulrich, R. L., Ribot, W. J., Brueggemann, E. E., Hines, H. B., Chen, D., Lipscomb, L., Kim, H. S., Mrázek, J., Nierman, W. C., and Deshazer, D. 2007. Type VI secretion is a major virulence determinant in Burkholderia mallei. Mol. Microbiol. 64:1466-1485.

Shalom, G., Shaw, J. G., and Thomas, M. S. 2007. In vivo expression technology identifies a type VI secretion system locus in Burkholderia pseudomallei that is induced upon invasion of macrophages. Microbiology 153:2689-2699.

Si, M., Zhao, C., Burkinshaw, B., Zhang, B., Wei, D., Wang, Y., Dong, T. G., and Shen, X. 2017. Manganese scavenging and oxidative stress response mediated by type VI secretion system inBurkholderia thailandensis. Proc. Natl. Acad. Sci. U.S.A. 114:E2233-E2242.

Silverman, J. M., Brunet, Y. R., Cascales, E., and Mougous, J. D. 2012. Structure and regulation of the type VI secretion system. Annu. Rev. Microbiol. 66:453-472.

Simon, R., Priefer, U., and Puhler, A. 1983. A broad host range mobilization system for in vivo genetic engineering: Transposon mutagenesis in gram negative bacteria. Nat. Biotechnol. 1:784-791.

Suzuki, S., Aono, T., Lee, K.-B., Suzuki, T., Liu, C.-T., Miwa, H., Wakao, S., Iki, T., and Oyaizu, H. 2007. Rhizobial factors required for stem nodule maturation and maintenance in Sesbania rostrata-Azorhizobium caulinodans ORS571 symbiosis. Appl. Environ. Microbiol. 73:66506659.

Tamura, K., Stecher, G., Peterson, D., Filipski, A., and Kumar, S. 2013. MEGA6: Molecular evolutionary genetics analysis version 6.0. Mol. Biol. Evol. 30:2725-2729.

Tseng, T.-T., Tyler, B. M., and Setubal, J. C. 2009. Protein secretion systems in bacterial-host associations, and their description in the gene ontology. BMC Microbiol. 9 (Suppl 1):S2.

Tsukada, S., Aono, T., Akiba, N., Lee, K.-B., Liu, C.-T., Toyazaki, H., and Oyaizu, H. 2009. Comparative genome-wide transcriptional profiling of Azorhizobium caulinodans ORS571 grown under free-living and symbiotic conditions. Appl. Environ. Microbiol. 75:5037-5046.

Venkateshwaran, M. 2015. Exploring the feasibility of transferring nitrogen fixation to cereal crops. Pages 403-410 in: Principles of Plant-Microbe Interactions: Microbes for Sustainable Agriculture. B. Lugtenberg, ed. Springer International Publishing, Cham.

Vergunst, A. C., Schrammeijer, B., den Dulk-Ras, A., de Vlaam, C. M. T., Regensburg-Tuïnk, T. J. G., and Hooykaas, P. J. J. 2000. VirB/D4dependent protein translocation from Agrobacterium into plant cells. Science 290:979-982.

Wenren, L. M., Sullivan, N. L., Cardarelli, L., Septer, A. N., and Gibbs, K. A. 2013. Two independent pathways for self-recognition in Proteus mirabilis are linked by type VI-dependent export. MBio 4:e00374-13.

Wielbo, J., Kuske, J., Marek-Kozaczuk, M., and Skorupska, A. 2010. The competition between Rhizobium leguminosarum bv. viciae strains progresses until late stages of symbiosis. Plant Soil 337:125-135.

Wu, C.-F., Lin, J.-S., Shaw, G.-C., and Lai, E.-M. 2012. Acid-induced type VI secretion system is regulated by ExoR-ChvG/ChvI signaling cascade in Agrobacterium tumefaciens. PLoS Pathog. 8:e1002938.

Wu, H.-Y., Chung, P.-C., Shih, H.-W., Wen, S.-R., and Lai, E.-M. 2008. Secretome analysis uncovers an Hcp-family protein secreted via a type VI secretion system in Agrobacterium tumefaciens. J. Bacteriol. 190: 2841-2850.

Zheng, J., and Leung, K. Y. 2007. Dissection of a type VI secretion system in Edwardsiella tarda. Mol. Microbiol. 66:1192-1206.

Zoued, A., Brunet, Y. R., Durand, E., Aschtgen, M.-S., Logger, L., Douzi, B., Journet, L., Cambillau, C., and Cascales, E. 2014. Architecture and assembly of the type VI secretion system. Biochim. Biophys. Acta 1843: 1664-1673. 